Review Article

\title{
Advances in the Use of Nanocomposite Membranes for Carbon Capture Operations
}

\author{
Emmanuel E. Okoro $\mathbb{D}^{1,2}$ Rachael Josephs, ${ }^{1}$ Samuel E. Sanni ${ }^{1},{ }^{3}$ and Yuven Nchila ${ }^{1}$ \\ ${ }^{1}$ Petroleum Engineering Department, Covenant University, Ota, Nigeria \\ ${ }^{2}$ Petroleum Engineering Department, University of Port Harcourt, Choba, Nigeria \\ ${ }^{3}$ Chemical Engineering Department, Covenant University, Ota, Nigeria \\ Correspondence should be addressed to Emmanuel E. Okoro; emeka.okoro@covenantuniversity.edu.ng
}

Received 24 October 2020; Revised 4 December 2020; Accepted 8 June 2021; Published 19 June 2021

Academic Editor: Prem Kumar Seelam

Copyright ( $) 2021$ Emmanuel E. Okoro et al. This is an open access article distributed under the Creative Commons Attribution License, which permits unrestricted use, distribution, and reproduction in any medium, provided the original work is properly cited.

\begin{abstract}
The adoption of nanodoped membranes in the areas of gas stream separation, water, and wastewater treatments due to the physical and operational advantages of such membranes has significantly increased. The literature has shown that the surface structure and physicochemical properties of nanodoped membranes contribute significantly to the interaction and rejection characteristics when compared to bare membranes. This study reviews the recent developments on nanodoped membranes, and their hybrids for carbon capture and gas separation operations. Features such as the nanoparticles/materials and hybrids used for membrane doping and the effect of physicochemical properties and water vapour in nanodoped membrane performance for carbon capture are discussed. The highlights of this review show that nanodoped membrane is a facile modification technique which improves the membrane performance in most cases and holds a great potential for carbon capture. Membrane module design and material, thickness, structure, and configuration were identified as key factors that contribute directly, to nanodoped membrane performance. This study also affirms that the three core parameters satisfied before turning a microporous material into a membrane are as follows: high permeability and selectivity, ease of fabrication, and robust structure. From the findings, it is also observed that the application of smart models and knowledge-based systems have not been extensively studied in nanoparticle-/material-doped membranes. More studies are encouraged because technical improvements are needed in order to achieve high performance of carbon capture using nanodoped membranes, as well as improving their durability, permeability, and selectivity of the membrane.
\end{abstract}

\section{Introduction}

The carbon dioxide $\left(\mathrm{CO}_{2}\right)$ volume in the atmosphere has increased since the industrial age, and this can be attributed to the anthropogenic activities. $\mathrm{CO}_{2}$ is an effective greenhouse gas from the literature, due to its ability to absorb Earth's surface infrared radiation emission. The higher the concentration of carbon dioxide in the atmosphere, the more infrared accumulates and the average temperature of the lower layers of the Earth's atmosphere increases. This process is called global warming [1]. Carbon Capture Utilization and Storage (CCUS) technology is evolving in response to global warming and climate change. CCUS is the process of extracting $\mathrm{CO}_{2}$ from a variety of high- temperature treatment plants and processes using a variety of technologies [2]. Along with the introduction of CCUS technology, $\mathrm{CCU}$ aims to use $\mathrm{CO}_{2}$ as a source of carbon to create value from readily available raw materials [3].

Carbon capture technologies can be applied at different process stages and these include precombustion, postcombustion, and oxyfuel combustion. Technologies used in postcombustion $\mathrm{CO}_{2}$ capture are as follows: absorption by chemical solvent, pressure/vacuum swing adsorption, adsorption by solid sorbent, cryogenic separation, membrane separation, and more recently microbial/algae separation [4]. Although cryogenic separations are energy-intensive, chemical absorption and physical adsorption are becoming increasingly important, while most membrane separation 
technologies are progressively developing. Those of precombustion include absorption by chemical solvents, absorption by physical solvents, and adsorption by porous organic frameworks [4]. Oxyfuel combustion technologies from the literature include chemical looping combustion, combustion in pure oxygen, and chemical looping reforming. Some issues affecting carbon capturing technology efficiency include low adsorption capacity at high temperatures, poor absorption, low mass transfer coefficient, and so on [5].

Nanotechnology is being used to enhance and optimize the efficiency of the existing membrane technologies for $\mathrm{CO}_{2}$ capture [6]. The part of nanomaterials in $\mathrm{CO}_{2}$ capture shows great potential because of its large surface area and excellent performance. This study reviews the application of nanocomposites in different process stages, trends in the absorption and adsorption of $\mathrm{CO}_{2}$, influence of physicochemical properties, nanoparticle/material type, and water vapour on carbon capture efficiency; moreover, an emphasis is placed on the use of nanodoped membranes in carbon capture. Finally, it highlights the challenges in nanodoped membrane technology for carbon capture process and therefore proposes areas for future research.

\section{Carbon Capture Background}

Precombustion technology captures $\mathrm{CO}_{2}$ before the combustion process occurs resulting in cleaner fuel through the combustion process and eases the separation of $\mathrm{CO}_{2}$ after the operation; thus, producing less $\mathrm{CO}_{2}$ emissions [7]. Two (2) examples are ammonia production and gasification of coal in power plants. In ammonia production, the $\mathrm{CO}_{2}$ coformed with hydrogen through the steam reforming process are detached before the ammonia synthesis occurs [8]. In the gasification process, fuels such as natural gas are converted directly into syngas by reforming. Precombustion technologies include absorption by chemical solvents such as amine-based solvents, which for instance are alkali compounds [9].

In oxyfuel combustion, inert gases are removed from the flue gas combustion. In this technique, fuel is burned with highly pure oxygen as a substitute of air to achieve complete combustion. This results in the formation of high concentrations of carbon dioxide and a small amount of water vapour in the flue during combustion. Currently, the oxygen used in the combustion process is provided by cryogenic air separation equipment. In the cryogenic air separation unit, oxygen is separated from the air by cryogenic condensation at low temperatures [10]. As shown in Table 1, oxygen fuel alternatives include chemical looping combustion and remodeling. Both use metal oxides to selectively transmit oxygen to the combustion chamber from the air. As chemical looping remodeling uses less stoichiometric oxygen volume, it produces syngas; thus, it can be seen as a suitable technique for syngas production or generation. One challenge, however, is to use the system at the high pressure required to realize the efficiency comparable to modern oxyfuel or postcombustion capture processes [8].
The postcombustion method is based on the separation of $\mathrm{CO}_{2}$ after the fuel is burned. This approach is feasible because it can be installed in existing industries without excessively changing its operating structure. The technology of carbon dioxide capture after combustion is principally based on fluid absorption, solid adsorbent adsorption, and membrane separation [4]. Between these knowledge, the utilization of solid adsorbents for capture sequestration is considered cheaper and easier than the scientifically advance fluid absorption process. However, chemical absorption is reported to be the most appropriate physical adsorption method for postcombustion capturing of carbon dioxide in power plants [11]. The choice of adsorbent is vital in determining the final efficiency of the adsorption technology used to selectively remove and capture $\mathrm{CO}_{2}$. Various types of adsorbents have been exploited for carbon dioxide, such as zeolites, activated carbon, and organometallic frameworks [5].

Changes in temperature or pressure promote adsorption, leading to temperature oscillation (TSA) adsorption and pressure oscillation (PSA) adsorption, respectively [7]. The main focus in this direction is on porous materials, including microporous, mesoporous, zeolites, carbonate materials, organometallic frameworks, and related amino-functionalities. Zeolite has a high adsorption capacity for higher $\mathrm{CO}_{2}$ partial pressure, when compared with other adsorbents. However, due to competitive adsorption, low $\mathrm{CO}_{2}$ adsorption capacity in the presence of water is often observed due to high affinity of these materials for water [12]. Membranes, on the other hand, provide better performance due to their properties and processability, but efforts to improve permeability are usually made to the detriment of selectivity and vice versa [7]. Membrane separation is a comparatively new technology for $\mathrm{CO}_{2}$ separation. It uses different gas solubility, diffusion coefficient, adsorption, and absorption differences of various materials for separation.

Membrane separation is one of the most efficient separation methods where high-purity products are not required, as they are highly efficient contrasted with other separation systems. Membrane separation is currently being studied in detail due to its many merits in terms of technical aspects, in addition to cost factors, compared to other separation methods. In addition, its application is very flexible because it can be used in precombustion and postcombustion approaches [7]. The main limitation of separation after combustion by membrane technique is the need for very high selectivity for the extraction of relatively low $\mathrm{CO}_{2}$ concentrations from exhaust gases. Therefore, the development of a suitable membrane material is very important to meet the requirements set by the International Energy Agency (IEA). Therefore, selectivity is very important and low selectivity is a serious problem in the commercialization of this process, as membrane properties such as porosity, wettability, and pore size are vital to the process efficiency [13].

According to the literature, nanomaterials are considered more effective due to their excellent properties, which highlights them to be used in doping membranes as potential for $\mathrm{CO}_{2}$ capture technique with its thermal stability advantages $[14,15]$. 
TABLE 1: $\mathrm{CO}_{2}$ capture membranes.

\begin{tabular}{|c|c|c|c|}
\hline Type of membrane & Membrane preparation & $\begin{array}{l}\text { Temperature } \\
\text { range }\left({ }^{\circ} \mathrm{C}\right)\end{array}$ & Area of application \\
\hline Polymer-based & Phase inversion process & $<100$ & $\begin{array}{l}\mathrm{CO}_{2} \text { capture from natural gas, } \\
\text { biogas, and flue gas }\end{array}$ \\
\hline Dual-phase & Etching method & $400-700$ & $\begin{array}{l}\mathrm{CO}_{2} \text { and oxygen from various gas } \\
\text { mixtures }\end{array}$ \\
\hline $\begin{array}{l}\text { Oxygen ion-conducting } \\
\text { ceramics }\end{array}$ & Sequence of extrusion, and sintering technique & $>700$ & $\mathrm{CO}_{2}$ separation after combustion \\
\hline Membrane contractors & Extrusion, and sintering technique & $<100$ & $\mathrm{CO}_{2}$ absorbed in a solvent \\
\hline Carbon-based & Vacuum-assisted coating process & $<100$ & Separation of $\mathrm{CO}_{2}$ from biogas \\
\hline Air liquid hollow fiber & Interfacial polymerization technique & $<100$ & $\mathrm{CO}_{2}$ capture from flue (stack) gas \\
\hline Single-layer graphene & $\begin{array}{l}\text { Ozone functionalization-based etching and pore- } \\
\text { modification chemistry }\end{array}$ & - & Postcombustion $\mathrm{CO}_{2}$ capture \\
\hline $\begin{array}{l}\text { Thermal rearranged } \\
\text { polymer }\end{array}$ & Crosslinked thermally rearranged polymer & $<100$ & $\mathrm{CO}_{2}$ removal \\
\hline $\begin{array}{l}\text { Polymers of intrinsic } \\
\text { microporosity }\end{array}$ & $\begin{array}{l}\text { Polymerization reaction based on a double-aromatic } \\
\text { nucleophilic substitution mechanism }\end{array}$ & $<100$ & $\mathrm{CO}_{2}$ removal \\
\hline Perfluoro-polymer & Impregnation and coating & $>70$ & $\begin{array}{c}\mathrm{CO}_{2} \text { removal from raw natural gas } \\
\text { treatment }\end{array}$ \\
\hline Zeolite-based inorganic & In situ hydrothermal synthesis method & $>100$ & $\mathrm{CO}_{2}$ separation and removal \\
\hline Mixed matrix & Spin coating & $<100$ & $\mathrm{CO}_{2}$ separation and removal \\
\hline
\end{tabular}

Experimental synthesis of various nanoparticles has been proven to effectively capture carbon dioxide at high temperatures, and various nanocomposite materials have been used in membrane separation processes to optimize carbon capture efficiency. Figure 1 shows the carbon capture technology, and the analysis is based on three identified carbon capture process paths [14].

One of the main problems with postcombustion combustion is the separation of relatively low $\mathrm{CO}_{2}$ concentrations (usually about $3-15 \%$ by volume) from large amounts of nitrogen in the exhaust. The process also requires a lot of energy for solvent regeneration. The largest postcombustion operating unit has a capacity of about 800 tones $\mathrm{CO}_{2}$ per day [15]. Several postcombustion $\mathrm{CO}_{2}$ exist, amongst which include absorption (which is the most widely used in oil and chemical industries and involves use of solvent to remove the $\mathrm{CO}_{2}$ from the flue gas) and membrane (involving physical or chemical interactions between membrane material and gases) [16]. In precombustion process, the $\mathrm{CO}_{2}$ content is in the range of 15-60 mole percentage at high pressure. Precombustion technique is used for hydrogen large-scale production to manufacture fertilizer and ammonia manufacture. This capture technique is more efficient, but the base gasification process's capital costs are often more expensive because of its complicated installation than the traditional pulverized coal power plants [17]. Oxyfuel combustion usually results in gas with high $\mathrm{CO}_{2}$ concentration, often higher than $80 \%$ by volume. This technique often entails the separation of oxygen from air with an estimated oxygen purity greater than $95 \%$. The oxyfuel combustion system is still being proven.

The choice of technical conception is largely determined by the conditions of the process under which it must operate. Higher collection efficiency can be achieved, although this will considerably require larger separation devices and more energy and cost. Theoretically, oxyfuel combustion systems can capture nearly all the $\mathrm{CO}_{2}$ produced. This capture technique needs additional gas treatment systems to remove nitrogen and sulfur pollutants [18].

\section{Membranes}

Membrane engineering is a physical process that often involves the use of a semipermeable barrier in containment and permeability flows to separate gas mixtures of two or more components. Membrane separation allows certain molecules to pass through while blocking some specific molecules from passing through the membrane (Figure 2) [19]. Membrane technology in carbon capture and storage (CCS) has advantage over other technologies because of ease of installation, and compatibility (such as offshore). In addition, it offers flexibility of operation and maintenance, reduced capital cost and energy consumption, and it requires less chemicals when related to other separation processes.

In membrane engineering, the desired components selectively permeate, and unwanted components are retained, thus, separating the mixture. Various membranes have been developed for the capture of $\mathrm{CO}_{2}$ with energy efficiency and low cost to mitigate carbon emission [20], and the membrane separation technology has been identified as one of the most efficient solutions for carbon sequestration. Ji and Zhao [21] highlighted that gas stream separation using membrane technology is still evolving and has attracted intensive research into CCS in recent years. The selectivity of a particular membrane with respect to the gas stream ratio of permeabilities is dependent on the type of membrane, molecular weight and size, affinity to membrane material, membrane thickness, and so on [22].

Membrane material has their strengths and shortcomings in terms of material cost, separation properties, and durability. To reduce carbon recovery costs, it is important 


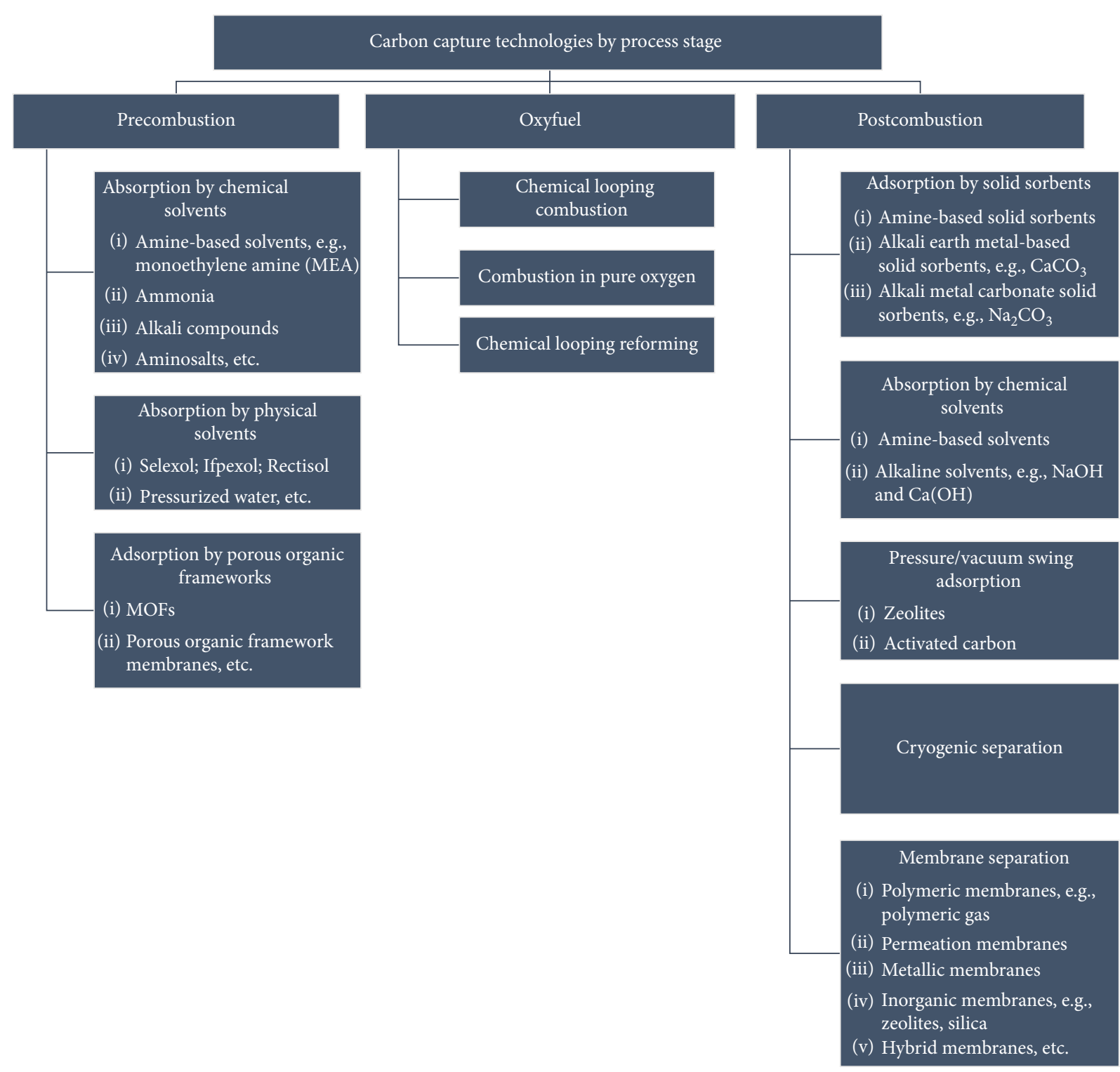

Figure 1: Carbon capture technologies by process stage.

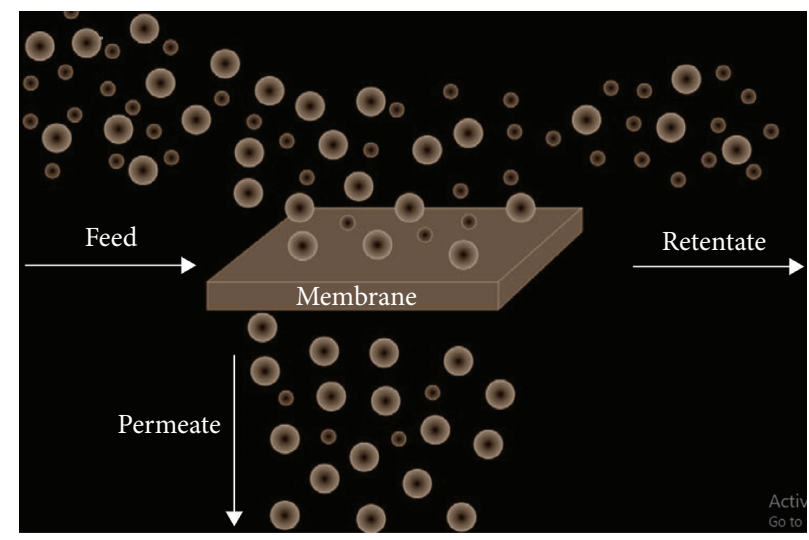

FIGURE 2: Membrane for gas stream separation. 
to develop advanced membrane materials to increase profitability. Various membranes such as polymer films, carbon molecular sieve membranes, mixed matrix technology, microporous organic polymers, and inorganic membranes (metal, zeolite) can be used for separation of $\mathrm{CO}_{2}$-associated gas streams [23]. To achieve a high flow rate, the supply gas is compressed and the permeable gas is combined with a vacuum to achieve an advanced driving force. Subsequently, the membrane is only a few hundred nanometers to a few micrometers thick, and most membranes in their natural form cannot resist the force of the pressurized feed gas [24]. Therefore, the membrane is generally coated or doped on a thick and permeable substrate to obtain sufficient mechanical strength. Some of the membrane features are that it must have minimal flow resistance and contain large pores to allow free flow of gas through the cover layer [25].

Koros and Mahajan [26] used the mechanism of separation to classify gas separation membranes into sorption diffusion, complex sorption diffusion, and ion-conducting membranes. Most commercial gas separation membranes are currently cheaper to produce than inorganic materials and offer some attractive properties, such as flexibility in both flat and hollow fibers. Organic membranes or polymeric membranes are the mainstream. In practice, it has been shown in the literature that polymeric membranes used operate mainly according to the solution diffusion mechanism [27]. By this mechanism, the gas molecules in the feed stream are first absorbed by the membrane, diffused through the membrane matrix, and then absorbed from the permeable side. Dense/tight membranes are often used as a selective barrier between the supply stream and the permeable gas stream. The efficiency of a membrane selectivity depends on the matrix of the membrane diffusibility and solubility. In order to obtain the desired properties, the material for synthesizing the type of membrane to be adopted must be selected correctly [28]. For this reason, different types of membranes have been specially designed for $\mathrm{CO}_{2}$ removal.

Table 1 shows the different types of membranes for separating $\mathrm{CO}_{2}$-related gas streams before or after combustion processes and their temperature ranges. The literature shows that ceramic membranes can be used for higher temperature in catalytic membrane reactors $[29,30]$. He et al. [31] developed a single-layer graphene membrane that exceeds postcombustion capture targets by some margin. The functionalized $\mathrm{CO}_{2}$-selective polymer chains in the nanoporous graphene allowed for the production of $\mathrm{CO}_{2}$ selective membrane thickness on the order of nanometers. The two-dimensional nature of the membrane significantly increases the permeability to $\mathrm{CO}_{2}$, which makes the membranes even more attractive for carbon capture. Siagian et al. [19] conducted a review on membrane gas separation and contactor. Their study compared both technologies that use features, such as carbon capture performance, characteristics, and techno-economic assessment. They highlight the need to develop novel generation of membrane with optimal pressure, temperature, and mechanical stability, as well as high selectivity and permeability. In order to prepare membranes for separation, two aspects should be considered: the morphology of the developed film and the nature of the material used (whether inorganic or organic).

The selective membrane must not only be able to process organic vapors at high temperatures, but all other components within the module must also be durable. A number of separations problems have been clearly shown in the literature to deviate from isothermal conditions and therefore cannot be ignored [32]. When the carbon dioxide is separated from the gas stream, the temperature of the permeate drops as a direct result of the Joule-Thomson (JT) effect. The temperature drop observed on the high-pressure side is an indirect result of the JT effect, which is caused by mass permeation through the membrane as heat is transferred through the membrane along with the enthalpy due to the mass passing through the membrane. It can be seen that the temperature change in the unit depends largely on the stage cut and the concentration of $\mathrm{CO}_{2}$ in the feed. In some cases, a gas mixture containing more $\mathrm{CO}_{2}$ in the supply will have a larger temperature difference than the supply in the rest of the unit. This is because the composition of the raw material not only changes the amount of osmotic gas passing through the membrane wall, but also the thermodynamic properties of the residue and the gas mixture in the filtrate [33]. It is generally assumed that the value of gas permeability is temperature independent and separates the effects of gas phase composition and gradual cuts on temperature changes caused by expansion. However, the temperature variation in the unit is observed to vary greatly. Most membranes undergo thermal degradation in a wide temperature range.

Depending on the type of membrane separation process, operating conditions may include hydraulic pressure, osmotic pressure, feed cross flow velocity, and temperature. Operating conditions can affect both solute rejection and permeate flux. Between these parameters, the filtrate flow is very sensitive to the temperature of the feed material. The filtrate flow increases as the feed temperature increases. This is mainly due to the decrease of feed viscosity with an increase in the raw material temperature. More specifically permeate flux typically increases as temperature increases in a linear relationship with viscosity. Furthermore, under fixed temperature condition, the concentration ratio has a fixed distribution Coefficient-Ostwald coefficient [34]. The literature has shown that temperature has a great influence on permeability coefficient, that is, with a rise in feed gas stream temperature, the permeability coefficient of the membrane material increases. This relationship is so, because with an increase of temperature, the kinetic energy of gas molecule becomes greater, so also the diffusion coefficient and moreover the solubility coefficient also becomes greater with the increase of temperature [34]. Since the permeability coefficient is obtained as a function of solubility coefficient and diffusion coefficient, it naturally increases with increasing temperature, which affects the penetration process. Normally, the solubility decreases with increasing temperature and the diffusion coefficient increases.

Various membrane designs have been proposed as costeffective $\mathrm{CO}_{2}$ capture options $[35,36]$. To improve the performance of polymeric membranes, various resolutions have been proposed with particular importance on 
exploiting the selectivity size or shape provided by dispersed nanoporous materials in combination with the polymer processability and mechanical stability. To this end, various polymers were modified with inorganic fillers to evenly disperse the filler particles in a polymer matrix to give a mixed matrix membrane (MMM) [12]. Glassy-polymers generally lead to MMMs with improved release characteristics, while highly permeable and poorly selective gummy polymers are unlikely to be effective as MMMs when inorganic fillers are used. Some of the limitations of MMM are the porosity of the polymer blocked filler, filler and polymer poor compatibility, and segregation of the filler.

Porous inorganic microporous membranes have generated considerable interest in the investigation of $\mathrm{H}_{2}$ separation in both experimental and potential industrial applications. The main inorganic microporous membrane transfer mechanisms in the literature are as follows [4]:

(1) Knudsen diffusion due to collisions between different gases,

(2) Surface diffusion, due to gas adsorption on the pore walls, and

(3) Molecular sieve, where small molecules pass through and large molecules are blocked by the sieve.

Silica membranes have the potential to be applied at industrial stage due to their high selectivity, optimum temperature stability, and their low cost. As a general rule, membranes based on silicon dioxide obtained by chemical vapour deposition or chemical vapour phase impregnation have an $\mathrm{H}_{2} / \mathrm{CO}_{2}$ selectivity of up to 50 , which is significantly higher than the Knudsen values [37, 38].

One of the drawbacks of silica membranes is their susceptibility to large amounts of water vapour, as this contributes to reduced performance. New research focuses on the creation of hybrid silica membranes that can improve hydrothermal stability and separation efficiency in the presence of significant water vapour [39]. Niobium-doped silica membrane shows enhanced hydrothermal stability in almost practical conditions. Silica membranes doped with about $17 \%$ or $33 \%$ niobium gave stability of 300 hours in the presence of water vapour while maintaining $\mathrm{H}_{2} / \mathrm{CO}_{2}$ selectivity of about 1500 [40]. Carbon membranes are produced by carbonization at extreme temperatures $(700-1200 \mathrm{~K})$ in an inert atmosphere, creates a microporous membrane that acts as a molecular sieve that provides surface diffusion [3]. According to Favvas et al. [41], this leads to a significant improvement in selectivity and permeability.

The carbon molecular sieve membrane obtained by carbonizing the hollow fiber copolyamide membrane BTDA-TDI/ MDI (R84) has a $\mathrm{H}_{2} / \mathrm{CO}_{2}$ selectivity of 17 . Numerous endeavors have been made to improve the chemical and hydrothermal steadiness of the layer [42]. Metal membranes are best suited for $\mathrm{CO}_{2}$ separation prior to combustion due to their infinite selectivity. Metal membranes are often palladiumbased, and the hydrogen separation process is accomplished by hydrogen decoupling chemisorption at the membrane surface. Hydrogen then diffuses through the wire mesh due to the partial reduction in pressure on the opposite side of the film [8].
Disadvantages, such as embrittlement of the membrane because of low temperature phase transitions, can reduce the effectiveness of the membrane for large-scale operations. Mixed matrix membranes contain microstructures with inorganic material in the form of nanoparticles in a discrete phase, embedded in a continuous polymer matrix [43]. This concept combines the strong points of each stage: alluring mechanical properties, efficient interaction capacity of polymers, and high selectivity of the dispersed fillers. Usually, inorganic materials are added to a polymer matrix, which helps to enhance on the thermal and mechanical properties of the membrane hence increasing its adaptability in changing chemical and physical environments.

The applicability of membrane technology in carbon capture can be achieved at three stages, at the precombustion, postcombustion stage, and oxyfuel combustion stage. During the precombustion phase, these membranes are used to separate carbon dioxide from the exhaust gases before entering the combustion chamber [44]. In this process, the gaseous fuel is converted to a mixture of syngas $\left(\mathrm{H}_{2}\right.$ and $\left.\mathrm{CO}\right)$ and $\mathrm{CO}_{2}$, and then a gas-water substitution reaction is performed to reduce the $\mathrm{CO}$ content (equation (1)). The remaining $\mathrm{H}_{2}$ and $\mathrm{CO}_{2}$ is then separated using membrane technology:

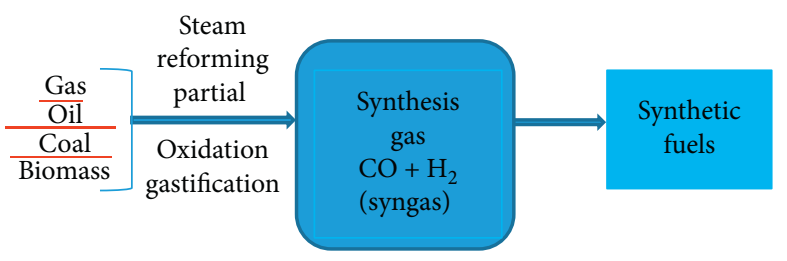

The temperature range for precombustion membrane application is between 300 and $700^{\circ} \mathrm{C}$ and pressures of up to 80 bar. During postcombustion, these membranes are used to separate $\mathrm{CO}_{2}$ after fuel combustion has occurred [45]. The flue gas often consists mainly of $\mathrm{CO}_{2}, \mathrm{~N}_{2}$, and $\mathrm{H}_{2} \mathrm{O}$. Postcombustion membranes separate $\mathrm{CO}_{2}$ and $\mathrm{N}_{2}$ gas at moderate temperatures and ambient atmosphere pressures. This is the most widely applicable $\mathrm{CO}_{2}$ separation method [46]. Some postcombustion membranes that have been commercially applied in $\mathrm{CO}_{2}$ include polymer-based and mixed matrix membranes. Oxyfuel combustion involves the utilization of pure $\mathrm{O}_{2}$ for combustion instead of air [47]. The flue gas composes mainly of $\mathrm{CO}_{2}$, water vapour, and $\mathrm{SO}_{2}$ impurities. Condensation process is used to eliminate the water and other process impurities. Examples of membranes used for oxyfuel combustion include fluorite-based and perovskite-based membranes.

The performance of membrane technology for gas separation is generally measured by its selectivity and permeability [48]. In order realize the anticipated performance (that is, high selectivity and permeability), appropriately selection of membrane material is vital. To achieve good mechanical strength, nanoporous membranes can be coated with a thick and porous substrate [49]. The supporting substrate should have large pore sizes to allow free gas flow through and offer low flow resistance. Kim et al. [50] 
highlighted that multistage membrane process is needed to capture and recover high-purity $\mathrm{CO}_{2}$ from off-gas with low $\mathrm{CO}_{2}$ concentrations with "no-mixing-loss."

\subsection{Membrane Gas Separation Selectivity and Permeability.} The purity of the product and recuperation rate are two key necessities for pragmatic gas separation. Ding [51] concluded that high membrane penetrability has restricted effect for applications in practical scenarios, while the same report highlighted the basic requirement for high membrane selectivity. For gas separation sets, practically all information points are underneath the clear line called "upper limit" in majority of the penetrable gas selectivity and permeability log-log plots (Figure 3). As new materials are created, the upper bound is raised. The upper bound theory generally shows that there is a hedge between selectivity and membrane performance. A highly penetrable membrane will in general be less selective and vice versa. The capacity to control the thickness of the partition layer and the conduct of the membrane material in the presence of impurities assumes a significantly more important part in the selection and improvement of new commercial membranes [52].

Equation (2) shows that membrane productivity is indirectly related to the thickness of the membrane layer. To manage the reduction in pressure across the film, it is in some cases important to build the thickness of the membrane division layer to decrease the productivity of the membrane, thus diminishing the measure of gas coursing through the cartridge. In addition to the pressure reduction on the gas supply side, the filtrate pressure accumulates on the permeate side of the membrane. This may be enough to have a serious impact on the performance of the membrane [53]:

$$
J=S \times D \times \frac{\Delta P}{l}=P \times \frac{\Delta p}{l},
$$

where $\Delta P$ represents the transmembrane differential pressure, $P$ is the coefficient of permeability, $l$ is the membrane thickness, $D$ is the diffusivity coefficient, and $S$ is the solubility coefficient.

For a region with limited membrane selectivity, the process of membrane separation will significantly benefit from a high selectivity, while in the region of limited pressure ratio, the advantage of high membrane selectivity is limited [51]. The design membrane process can be controlled by limiting concentration by separating the separations into stages. If the required gas concentration exceeds the critical concentration and the membrane selectivity is high enough, a single-stage unit can be used. If the needed gas concentration is below the limit, it becomes advisable to divide the process into two stages. The membrane in the first stage treats the gas up its limiting concentration, and then in the second stage, the membrane treats the gas to the desired purity. The first step is in the area of limited selectivity and can greatly benefit from the high selectivity of the membrane. The second step is a limited range of pressure ratios, and a membrane with moderate selectivity can be applied [54].

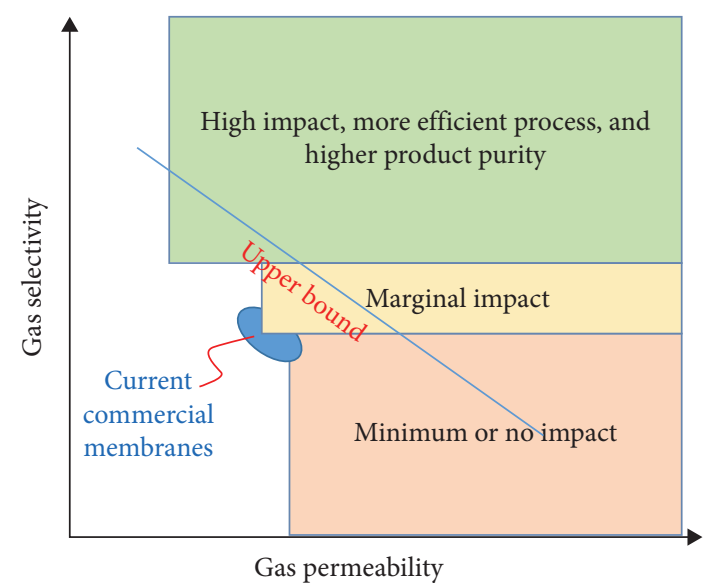

FIGURE 3: Relationship between membrane gas separation selectivity and permeability [51].

Poly (ethylene oxide) (PEO) containing polymeric membranes are highly $\mathrm{CO}_{2}$-selective and thus attractive for the separation of $\mathrm{CO}_{2}$-bound gases. However, the development of a membrane with a high PEO content is often difficult due to its low mechanical properties, the high tendency for PEO to crystallize and form a barrier to gas transport in the membrane [55]. The copolymers are considerably more stable mechanically, than those without pentiptycene and effectively suppress the crystallization of PEO due to the mechanism of amplification of the supramolecular chain and the exclusion of interactions caused by the structure of pentiptycene, leading to completely amorphous structure. The transportation of gas in PEO containing polymeric membrane depends on both the weight content of the PEO and the length of the PEO chain. Due to the competition between dissolution and diffusion coefficients, a nonlinear correlation is observed between $\mathrm{CO}_{2}$ permeability and PEO mass content, producing a copolymer that changes from solubility to size-selective [55].

In the case of multicomponent membranes, the detailed morphology of the microparticles, such as the shape of each phase and the dimensional arrangement (that is, connectivity), determines the properties of the membrane, which are sensitively influenced by the copolymer composition, the segment sequence length, and the interaction between the components [56]. Compared to diffusion-controlled transport, the solubility-selection process is mainly thermodynamic, with polymer affinity permeation interactions and penetration concentrate dominating the transport process. Despite the fact that the membrane for the most part provides the surface area for mass exchange, it has a significant effect on the execution of the process. Since the entire mass exchange occurs in the pores of the film, porosity and pore size enormously impact the productivity [57].

3.2. Selectivity Mechanism of the Membranes towards $\mathrm{CO}_{2}$ Separation. Membrane separation process has several advantages over other conventional separation methods. Firstly, the membrane process is a viable and energy-efficient alternative to carbon capture because it does not require 
phase conversion. Secondly, the required processing equipment is very straightforward and has no moving parts and it is compact, relatively simple to operate and handle; in addition, it is easily expandable [58]. The gas permeability of the membrane is a function of the properties of the membrane (physical and chemical structure), the properties of the permeable particles (size, shape, and polarity), and the interaction between the membrane and the permeable particles [59]. The first two, which are the properties of the membrane and the properties of the penetrating particles, determine the diffusion properties of a particular gas passing through a particular membrane. The third property, the interaction between the membrane and the permeable material, refers to the adsorption capacity or solubility of the gas in the membrane [60].

There are four main transport mechanisms that can be employed to calculate gas separation using porous membranes [61]. The basis of this molecular weight transfer (Knudsen diffusion) must be separated by surface interaction (surface diffusion and capillary condensation) and molecular size (molecular sieving). The movement of molecules within the thin pore channels of the membrane material occurs because the diffused molecules collide with the surface (wall) and not with each other. Since the partial pressure of the gas is the driving force of the transfer, the Knudsen transfer can be caused by concentration or by a pressure gradient. The relative permeability of every segment is not directly related to the square root of its molecular weight [62]. In the surface diffusion mechanism, the diffusing gas is adsorbed on the pore walls of the film and afterward transported easily over the surface towards diminishing the surface concentration. Various models have been utilized to portray the transport mechanism in thick membranes, for example, the solution diffusion model $[63,64]$, the pore flow model [65], and the thermodynamic irreversible model [66]. The solution diffusion model is by all accounts recognized by a greater part of membrane researchers. In this model [67], the process of mass transport consists of the three following steps; (1) sorption of gas from raw material to the membrane; (2) molecular diffusion of gas in the membrane; and (3) removing gas from the membrane on the downstream side of the membrane. In addition, the solution diffusion model is commonly used to describe the transport mechanism of polymer membranes. In polymer membranes, one very vital parameter is penetrating condensation. Normally, penetrants with higher critical temperatures are easily condensable and, in this way, more soluble in polymers. The diffusion coefficients are usually less than the solubility coefficients of penetrants in most polymeric membranes. Thus, the relative gas permeability coefficients in these membranes are dictated by the gas dissolvability and not by the gas diffusion coefficient, except if the penetrant is a little molecule whose diffusion coefficient is sufficiently high to make up for its lower solubility.

To achieve high separation ratios in systems such as $\mathrm{CO}_{2}$, the interaction between one of the gases in the feed stream and the membrane surface can be caused by chemical modification of the separation layers. Chemical modification creates stronger base centers in the membrane, which leads to a stronger binding of $\mathrm{CO}_{2}$ to the modified surface, rendering the surface partially irreversible [68]. The more bound $\mathrm{CO}_{2}$ is less mobile, and this results in a lower permeability of $\mathrm{CO}_{2}$ through the membrane. Cho et al. [69] concluded that surface diffusion can be used as a separation mechanism in a membrane when the membrane pore size is very small and the temperature is low. Kusakabe et al. [70] observed a decrease in separation factors and permeability with increasing penetration temperature. Furthermore, the $\mathrm{CO}_{2}$ molecules adsorbed on the surface of the membrane micropore synthesized by the zeolite prevented penetration during the separation process.

Stern et al. [71] found that the permeability properties of a given penetrant can be notably enhanced by replacing an appropriate functional group in the polymer that will incite specific interactions with the penetrant. Such interactions mostly increase the solubility of the penetrant in the polymer.

\section{Membranes Doped with Nanocomposites}

Membrane technology has emerged as one of the promising approaches for efficient purification, and the use of hybrid materials and interfacial control are the main mechanisms used to improve filtration optimization efficiency [72]. Wang et al. [73] emphasized that the changes in the properties and structure of the membrane due to the presence of nanoparticles depend on the dispersion of nanoparticles in the casting solution. Gao et al. [74] noted that modifying the membrane surface (i.e., changing the structure and properties of the surface) can further enhance its filtration performance. One of the routes for further improvement in membrane performance is the development of multifunctional materials, whereby the structure of these unique materials will naturally combine with the surface reactive moieties [75]. Incorporating nanoparticles or nanomaterials into host framework using substitution doping is an effective strategy to modulate the features of a membrane [76]. Ideal materials need to have an optimal surface area, tailorable porous structure, high thermal stability, and easy surface functionality [40]. Figure 4 shows a pictorial explanation of polymer nanocomposite membrane for gas stream separation.

Membrane-based gas separation has shown great potential in carbon capture owing to its merits of high energy efficiency, low capital cost, and small environmental footprint. However, the development of novel membrane materials with a combined high selectivity and permeability is in demand [77]. He [23] also concludes in his research that significant improvements on membrane material performance, process efficiency, and module are needed for advancement of membrane technology in $\mathrm{CO}_{2}$ capture. The adoption of nanocomposite-doped membranes has significantly increased due to their reduced operational footprint, high removal efficiency, and relatively low energy intensity. Researchers have devoted efforts to improve these membranes' performance by introducing new materials, novel nanoadditives, and developing new processes [78]. Copper oxide, carbon nanotube, polymeric nanoparticles, zinc 


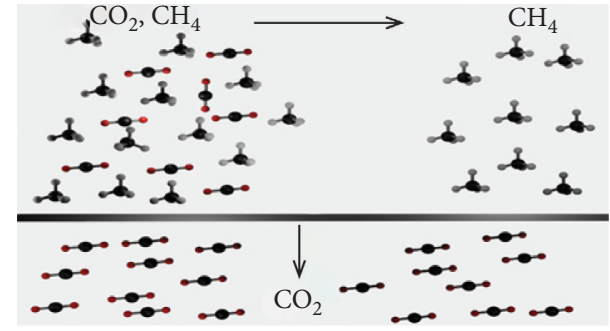

Figure 4: Polymer matrix forming nanocomposite membranes with enhanced gas permeability.

oxide, aluminum oxide, silicon oxide, zirconium dioxide, and titanium dioxide, for example, are among the nanoparticles/materials used for surface modification to overcome fouling issues [79]. However, poor dispersibility has been identified as one of the drawdowns in using the metal or metal oxides nanoparticles as a membrane surface modifier.

The membrane gas separation performance is dependent on several factors including membrane material, structure, thickness, and configuration (for example, hollow fiber and flat film), as well as module/system design. Various materials have been developed for $\mathrm{CO}_{2}$ capture membrane, including organic, inorganic, and organic-inorganic compounds, each with their own typical advantages and disadvantages [80]. Thus, Arumugham et al. [81] proposed the use of hybrid nanomaterial/particles as a modifying agent due to their extraordinary physicochemical properties, improved interfacial interaction, thermal stability, and mechanical strength. These hybrid nano-based particles/materials are receiving ever-growing attention in membrane separation process technique. Two commonly used control strategies for regulation and optimization of membrane layer channels include crosslinking adjacent sheets to reduce interlayer spacing to the size of a molecular sieve and functionalizing interlayer channels to increase physicochemical affinity or introduce light transport carriers [77]. Additional crosslinking or intercalating agents are generally required to achieve channel optimization. In addition, the literature has identified interlayer channel size as another dominant parameter that governs membrane separation efficiency [82].

Membranes can be synthesized by using a variety of methods, depending on the physical and chemical properties to be achieved and the resources available. Processes that include minimal product loss, controlled operating conditions, simple or flexible parameter control, high reaction rates, economical, and environmentally friendly conditions are desirable [83].

4.1. Nano-Based Particle/Material-Doped Membranes. Nanodoped membrane has shown a good efficiency in most cases for $\mathrm{CO}_{2}$ capture or separation approach from flue gas streams. These nanoparticles/materials play a vital part in the formation of an efficient gas transport path in the membrane so as to increase solubility. According to Sreedhar et al. [7], there are three ways to reduce $\mathrm{CO}_{2}$ emissions, and they include improved carbon capture and sequestration, reducing carbon footprint, and energy intensity. Julian [84] observed that the widely applied material for $\mathrm{CO}_{2}$ removal or separation for membrane technology in the industry is polymer-based. The choice of polymer is because their manufacturing processes are not complex when compared to other materials, and the material cost is relatively inexpensive. The incorporation of nanosilica into polymeric membrane showed a significant increase in permeability which did not decrease the membrane selectivity [85]. This phenomenon can be attributed to the gas-permeable nanospace formed by the addition of the nanosilica particles. $\mathrm{Wu}$ et al. [86] improved molecular sieving efficiency of polyimide membrane by embedding nanocomposites. This was achieved by using organic polymer and inorganic material to develop an inexpensive membrane that provides molecular sieving efficiency.

Monocrystalline magnetite nanoparticles can respond to an external magnetic field, allowing for potentially easy placement/retrieval, thus reducing the need for separation energy and material consumption. Furthermore, magnetite is abundant and relatively stable in the environment. According to Li et al. [84], magnetic-based nanocomposites were also developed and evaluated for their sorption properties with respect to $\mathrm{CO}_{2}$ removal. Under high pressure, every magnetic nanocomposites showed a huge improvement in $\mathrm{CO}_{2}$ adsorption limit, due to sorption processes of both the functional groups (from the carbon substrates) and the iron oxide nanoparticles. When contrasted with other high selectivity membranes, the nanocomposite-doped membranes, having more well characterized structure, and can keep up their selectivity under high pressure and ultrahigh gas penetration properties [87].

Copolymer-doped nanocomposite membranes were studied at various feed pressures and compared to other membranes. According to Sreedhar et al. [7], the observed results were very positive and the resistance to contamination by these membranes makes them a good option for real systems. When compared to a typical membrane, the inclusion of nanomaterial/particle has been widely reported to significantly change the physicochemical properties of the membrane (hydrophilicity, porosity, charge thickness, layer toughness, warm, compound, and mechanical soundness) and has extraordinary potential in settling the compromise between permeability and selectivity. Despite significant advances in development of nanocomposite membranes, some problems must be solved before its practical large-scale applications. These problems include poor dispersibility of nanomaterials in polymer-based membranes, aggregation and weak chemical interactions between the nanocomposites and polymer matrix, incompatibility of nanomaterials with the polymer, and control alignment of nanocomposites in the active layer [7]. Several innovative approaches have been proposed to resolve these challenges, such as the modification of the nanocomposite surfaces or optimization of the embedding process, the development of new nanocomposite with specific pore structure/charge properties, and the optimization of the loading concentration and the durability of the nanocomposites membranes. 
The selection and use of suitable nanocomposite for the production of nanocomposite-doped membranes must depend on the technical properties of the feed to be processed, since there is no universal application of nanocomposites to dope any existing membrane for all types of applications. Membrane technology has a multidimensional character, which implies a high mass transfer rate and high selectivity in relation to a particular gas. In spite of the synthesis and assessment of hundreds, maybe even thousands of new materials, over $90 \%$ of the present commercial membranes are produced using less than 10 membrane materials, and the vast majority of which have been utilized for decades [88]. The literature has also shown that freshly prepared thin composite membranes usually lose $25 \%$ of their permeability in a few days and another $25 \%$ in the next week or two. In manufacturing useful membranes, one of the most important trade-offs is the choice between product purity and recovery. A single-pass membrane process can have a high-purity product or high product recovery, but achieving both requires a decent comprehension of the process. In some cases, chemical stability is an issue, while physical stability is more normal. Multilayer composite membranes contain many layers of various polymers. This is valuable on the grounds that the backing membrane makes up the most of the membranes and can be made of a relatively cheap material. How gases and vapors infiltrate through membranes is dependent upon the layer material and the structure of the gas. In the pore flow model, gases go through the layer through small pores and gas combinations are isolated by some type of molecular filtration; while the solution diffusion model expects that there are no lasting pores and that the gas dissolves in the membrane material as in a fluid. The dissolved gas at that point diffuses through the membrane by random diffusion in the concentration gradient [89]. Using a nanocomposite as a filler, Son et al. [91] created a new type of TFN membrane, into which a substrate with CNT was incorporated. The CNTs were first functionalized by oxidation before adding the polymer to the solution to form a support layer mixed with the CNTs. The interfacial polymerization process was used to create an active polyamide layer for the development of TFN membranes. Kononova et al. [92] emphasized that PI nanocomposites filled with silicate nanotubes and carbon nanofibers have shown a higher elastic modulus with an increase in the volume concentration of the nanocomposites without a catastrophic decrease in elongation at rest.

The effect of several nanoparticles, such as carbon nanofibers, nanocones/discs, halloisite hydrosilicate nanotubes, and yttrium-doped quasispherical zirconia particles, embedded in the Ultem-1000 polyetherimide was investigated by Gofman et al. [93]. The introduction of nanocomposites into a polymer increases the modulus of elasticity and the elastic limit of the base materials relative to unfilled polymeric material. Polyimide nanocomposite films (PI-PM), obtained from poly (amino acid) which has an optimized concentration of nanocomposites showed an increase in the modulus of elasticity with an increase in the concentration of nanocomposites of the order montmorillonite $>\mathrm{SNT}>\mathrm{ZrO}_{2}$. PI-PM films with $10 \%$ by volume SNT and $\mathrm{ZrO}_{2}$ showed higher fracture strains of the sample compared to PI-PM/montmorillonite films. This effect suggests that SNT and $\mathrm{ZrO}_{2}$ could more effectively improve the ductility of polyimide nanocomposites when relatively brittle polyimide montmorillonite films are not suitable [91]. The results confirm our expectations that the morphology of nanocomposites and, in particular, their height-to-width ratio strongly influence the viscoelastic properties of nanocomposites in solid and liquid state.

Yudin et al. [94], considered the inclusion of magnesium hydrosilicate NT in the polymer films enhanced their mechanical properties without significant increase in the brittleness. An increase in mechanical properties was also observed for composites containing up to $15 \%$ by weight of NT magnesium, along with an increase in thermal stability. Nanocomposite-doped membranes with improved performances such as high selectivity, fluxes, and good surface morphology have been achieved by integrating nanocomposites into a polymer matrix [94]. The modified membrane can exhibit excellent stability, high selectivity for target feed streams, and high molecular weight penetrant flux with low driving force under a wide scope of process conditions. The right decision of material for the matrix and sifter stages is fundamentally significant [95].

\subsection{Hybrid Nanocomposite-Doped Membrane. Current} studies have focused on developing hybrid membrane and application of nanoparticles/materials in the polymer matrix for gas separation and $\mathrm{CO}_{2}$ removal. Progress in improving membrane output with this hybrid theory is an idea for gas separation and morphological investigations of prevailing asymmetric and composite slim membranes [96-98]. Kusworo et al. [37] proposed the mix of UV illumination, thermal annealing, and ethanol- $\left.\mathrm{CH}_{3}\right)_{2} \mathrm{CO}$ to improve the exhibition of $\mathrm{PES}-\mathrm{TiO}_{2}$ nanohybrid membrane for carbon capture. The experimental results showed that the nanohybrid-PES-nano- $\mathrm{TiO}_{2}$ with a $0.5 \%$ loading by weight of nanoparticles had the best properties in terms of gas permeability $[99,100]$. The results also informed the fact that the combinations of UV irradiation, immersion in a mixture of ethanol-acetone, and combined thermal annealing treatments have shown the best performance.

Li et al. [101] highlighted the progress made in nanocomposite/hybrid CMS membranes for gas separation, and the hybrid nanoparticles were dispersed in a solvent to obtain a suspension by ultrasonic treatment. Hybrid ferrocene/PAA CMS membrane showed a higher gas permeability than pure CMS membrane due to the difference in the developed pore structure as a result of incorporation and pyrolysis of ferrocene. It was also observed that gas permeability improved as selectivity decreases with increasing ferrocene content. The best gas separation property in these hybrid ferrocene/PAA SMD membranes was observed with a precursor ferrocene content of $15 \%$ by weight, which has a gas permeability 22 times higher than that of a pure CMS membrane. In addition to surface modification and technology optimization, multicomponent composite and hybrid nanocomposites are becoming increasingly popular in 
membrane manufacturing due to the different options and properties offered by different combinations of nanocomposites. In terms of filtration performance, the hybrid nanocomposite membrane exhibited superior flux and solute repellency for mixed feed streams [102].

Some critiques indicate that hybrid nanocomposites commonly used in membrane manufacturing have high intrinsic costs for their raw materials and manufacturing technologies. Thus, more research is still needed to reduce the cost of hybrid nanocomposites and identify new hybrid nanocomposites at lower manufacturing costs.

\section{Physicochemical Properties of Membranes}

The characterization of a membrane to evaluate various properties is of great importance in research and development, since the design of various processes and membrane systems depend on reliable data on the properties of the membrane. Different membranes have various constructions that are answerable for their extraordinary functionality. The decision of a membrane for a particular partition process can be made dependent on its construction, porosity, surface movement, surrenders, mass exchange properties, morphology, compound design, and mechanical properties [7]. Porous micro/ultrafiltration membranes are ordinarily described by membrane flux, pore size and pore circulation, and molecular weight limit. Some physical and physicochemical properties of nanodoped membranes include surface area, density, interconnectivity, temperature, porosity, morphology, carbon capture sites, adsorption capacity, ability to withstand stress/strain, flexibility, selectivity, defects, and $\mathrm{CO}_{2}$ reduction performance are discussed below. Porosity is one of the main considerations which directly impacts the $\mathrm{CO}_{2}$ adsorption performance of the membranes [40]. Zainab et al. [40] built up a successful spider web like polyamide/carbon nanotube composite nanofibrous membrane impregnated with polyethyleneimine (PEI) for $\mathrm{CO}_{2}$ capture. The physicochemical properties were characterized using $\mathrm{N}_{2}$ adsorption/desorption, scanning electron microscopy (SEM), thermal gravimetric analysis (TGA), and Fourier transform infrared spectroscopy (FT-IR) techniques. The resultant nanofibrous membrane showed composite structure comprising of fine nanofibers and nanonets. This composite construction acts as a vessel for the storage of $\mathrm{CO}_{2}$ while the $-\mathrm{NH}_{2}$ sites of $\mathrm{CNTs}$ act as a device to pull in and catch $\mathrm{CO}_{2}$. The created membrane was then impregnated with PEI to upgrade the quantity of the $\mathrm{CO}_{2}$ capturing sites (that is, $-\mathrm{NH}_{2}$ ) on the surface. Notwithstanding, the presence of PEI-hindered inter- and intrafiber pores prompting decreased surface area and total pore volume. The integrated nanofiber composite membrane showed phenomenal mechanical qualities as well as remarkably tough adaptability contrasted with delicate sorbents [103].

Aside from single atom doping, heteroatom doping can essentially improve $\mathrm{CO}_{2}$ reduction performance because of the synergistic impact of various heteroatoms. The dopants cause variety in control thickness of the nanosheets that upgrade synergist action [76]. Among various polymers utilized for corrosive gas partition, the polyvinyl amine (PVAm) has the most promising potential. Because of the presence of large amine gathering and high level of hydrophilicity, it provides high permeability and selectivity for $\mathrm{CO}_{2}$ [104]. Thermodynamic properties of polymers assume a crucial part in the separation performance of membranes. Flory-Huggins hypothesis depicts the thermodynamics of polymer blends and solutions. It is a cross-section model that clarifies the nonideality of polymer combinations.

The $2 \mathrm{D}$ material membranes with very much characterized interlayer nanochannels possess extraordinary potential for precise molecular separation, where the size and surface synthetic property of the channel decide the separation effectiveness. The currently reported $2 \mathrm{D}$ material membranes for efficient $\mathrm{CO}_{2}$ separation are primarily built by introducing cross linkers or intercalators into the interlayer channel. The unique breathing effect and sizesieving effect jointly contribute to the high membrane separation performance with $\mathrm{CO}_{2}$ permeance of $150 \mathrm{GPU}$ and $\mathrm{CO}_{2} / \mathrm{CH}_{4}$ selectivity of 33 [78]. The high selectivity of $\mathrm{LDH}$ membranes can be explained by the synergy of breathing effect to $\mathrm{CO}_{2}$ and size-sieving mechanism. For most membranes, the separation factor of mixed gas is typically lower than the ideal selectivity of single gas due to the competitive sorption effects or $\mathrm{CO}_{2}$ plasticization, but the LDH membranes instead exhibit slightly higher gas selectivity for mixed gas separation [78]. The higher selectivity in $\mathrm{CO}_{2} / \mathrm{CH}_{4}$ mixture of $\mathrm{LDH}$ membranes is attributed to the intrinsic breathing effect of $\mathrm{LDH}$ material towards $\mathrm{CO}_{2}$ which renders the preferential adsorption and transportation of $\mathrm{CO}_{2}$, thereby hindering the transport of another component in gas mixtures [105].

The development of gas transmission channels using channel-like assembly such as nanoparticles has increased nanoparticle concentration reliance and $\mathrm{MMM}$ dependence on $\mathrm{CO}_{2}$ permeability without compromising $\mathrm{CO}_{2} / \mathrm{N}_{2}$ selectivity and also increased overall performance. The significance of the surface-modified structures has been investigated by comparing other silica nanoparticles without dendritic structures. The Maxwell model calculation first revealed the ultrahigh permeation of $\mathrm{CO}_{2}$ via the nanospace on the surface of the nanoparticles. MMMs are composed of gas-permeable nanoscale particles with excellent potential as large-scale and highly efficient $\mathrm{CO}_{2}$ separation membranes [106]. Surface modifications of the dendritic nanoparticle are another important approach to enhance their properties, which include but not limited to hydrophobic nature or hydrophilic or affinity between the substituent of the surface and $\mathrm{CO}_{2}$. Therefore, nanoparticles play an important role in the formation of efficient gas transport channels in polymeric membranes or in their interaction with $\mathrm{CO}_{2}$ and are expected to be significantly more soluble than other gases. The proposed approach for determining the nanostructures and physicochemical properties of nanosheets is believed to provide an alternative to the creation of membranes based on 2D gas separation materials [107].

Recently, a novel class of polymers, so-called "polymers of intrinsic microporosity (PIMs)," has emerged as a promising membrane material for gas separation. PIMs 
possess high free volumes and high surface areas, which can be mainly ascribed to their rigid and twisted aromatic ladder-like structures.

\section{Structure-Property Relationship in Membranes}

Expanding the structural variety of nanoparticles/materials is desirable to better understanding the structure-property relationships. Particle-shaped sorbent materials have been identified from the literature as a potential energy-efficient carbon capture and separations technology [76]. In addition, transformation of nanomorphologies on the membrane surface has been highlighted as novel approach for permeability improvement [108]. The performance of membranes is affected by the operating conditions such as temperature and pressure. Wu et al. [109] proposed a combination of covalent organic frameworks and mixed matrix membranes to improve the selectivity of membrane during gas separation process. The experimental results showed an enhancement of $116 \%$ in $\mathrm{CO}_{2}$ permeability and $27.6 \%$ improvement in selectivity of $\mathrm{CO}_{2} / \mathrm{CH}_{4}$ stream. The literature has also shown unselective pore in some mixed matrix membranes, and this has been attributed to an agglomeration of inorganic materials which can be disadvantageous in gas separation efficiency.

The agglomeration of nanoparticles deforms the active surface of the membrane due to the creation of a nonselective void that occurs between the polymeric material of the membrane and its inorganic particles. These cavities were created as a result of detachment from the surface of the nanoparticles and matrix. The void causes a Knudsen diffusion mechanism with a high permeability, but the selectivity is poor. Thus, inclusion of inorganic particles in the membrane (organic) is a crucial step for gas separation [110]. Rezakazemi et al. [111] and Zou et al. [112] observed that thermal annealing process helps both the inorganic particles and polymer membrane material to unify, thus improving the overall membrane performance in terms of selectivity and permeability. Kusworo et al. [85] also observed that UV light does improve the surface structure of membrane by reducing the available nonselective voids present between the inorganic particles and polymer materials. The exposure time also contributes to the selectivity output of the produced membrane; that is, the longer the irradiation time of the UV rays, the greater the likelihood of rearranging the existing surface structure of the membrane.

For idea morphological structure when considering some class of nanodoped membranes, a joint solvent that will increase the formation of a bridge between the inorganic and polymer compounds might be needed to provide much better permeability performance. Maxwell's model showed that dense filled membranes with fillers (such as nanomaterials/particles) will decrease gas permeability through some nanohybrid membrane [113]. According to observation by Suleman et al. [114], high concentration of nanoparticles/materials can decrease nanodoped membrane selectivity, while membranes doped with optimal concentrations of nanoparticles will most likely have a more stable membrane structure and surface dimensions that will improve its performance. Liu et al. [99] observed that avoiding the tendency of direct particle-particle contact will simplify separation processes for material collected and recycling as well as saving energy. Brinkmann et al. [115] described the temperature dependence of the transport properties of various multilayer membranes. Temperature affects both selectivity and permeability because permeability increased with temperature increase, whereas selectivity decreased.

The impact of membrane structure and thickness has been studied by Schuldt et al. [116]. Their study showed that at higher $\mathrm{CO}_{2}$ volatility (above 8 bar), membrane swell with $\mathrm{CO}_{2}$ leading to a selectivity decrease. Brinkmann et al. [115] examined pressure distribution in the membrane modules with membrane separation layers. Experimental data from previous work were compared with simulations based on modular flow trends and the free-volume model. For different operating conditions, different types of integrated membrane modules were used to simulate a virtual power plant. The energy consumption of the entire process was evaluated, and the membrane separation process could only compete with absorption when a $70 \%$ recovery and a $95 \% \mathrm{CO}_{2}$ purity were required and when a counter-current jacket design is applied. Another important issue that must be addressed before using membrane materials to separate gases is physical aging.

Aging process is common in glassy-polymers with defective chain packing structures, where the unbalanced elements having excessive free volume become encapsulated between the chains and act as a driving force for physical aging [117]. After aging, the collapsed membrane material chain structure contains less interstitial free volume for carbon atoms to move through. The aging-resistant properties of nanocomposite-doped membranes can be verified by the pure-gas permeation test over time, to observe the changes in normalized $\mathrm{CO}_{2}$ permeability of membranes upon aging. The most common way to address this problem is to use covalent bonds to cross the polymer network. Specific methods include thermal crosslinking, ultraviolet crosslinking, esterification, azide-based crosslinking, and carbon-induced crosslinking [118]. These methods often require special chemical modifications of the polymer with crosslinked functional groups. However, the introduction of small molecular fragments reduces the free volume of the polymer matrix that forms the rigid skeleton, which adversely affects the permeability of the membrane [119]. Thermal rearrangement polymer (TR) is a special case that increases the rigidity of the polymer chain through an intramolecular cyclization reaction. The resulting membrane exhibits a strong antiplasticization property. However, it often comes at the expense of mechanical stability, especially ductility. The incorporation of an inorganic filler into the polymer matrix to form a hybrid membrane is a promising alternative to improving the plasticization resistance of the membrane [120].

\section{Effect of Water Vapour on the Membrane Performance}

A membrane performance is quantified by its permeance, selectivity, and permeability. The permeability $\left(P_{A}\right)$ depends 
on the sorption coefficient $\left(S_{A}\right)$ and the diffusion coefficient $\left(D_{A}\right)$ according to a simple relationship for the membrane material:

$$
P_{A}=S_{A} D_{A} .
$$

It has also been found that fabrication parameters and water vapour strongly affect membrane performance. The presence of moisture and other contaminants will affect the performance of the membrane, thereby affecting the operating costs of the plant and this may affect the separation efficiency of the membrane [121]. Scholes et al. [122] applied a commercial membrane at a coal-fired power plant for carbon capture. The flow rate of the dry flue gas entering the membrane module at $45^{\circ} \mathrm{C}$ was $3.5 \mathrm{~kg} / \mathrm{h}$. Water condensation was observed on the membrane during the operation. After several hours of membrane operation, the permeability and selectivity decreased dramatically, which was attributed to the plasticization of the membrane and the membrane swelling due to the presence of water vapour. After some time, the permeability and selectivity recovered but did not reach their initial values [123]. Thus, humidity is one of the biggest challenges in the membrane transport properties.

The membrane used for gas stream separation process often suffers from membrane wetting, and as such, membrane for carbon capture is no exception. These phenomena severely limit membrane performance and the application of predictions based on ideal scenarios. Wetting the membrane significantly increases the resistance to mass transfer and leads to a significant decrease in the absorption capacity [124]. Liquid inlet pressure is commonly used to estimate the wettability of an absorbent liquid on a membrane [125]. Methods for reducing membrane wettability include using hydrophobic membranes, a dense surface layer composite membrane, selecting high surface tension liquids, and operating at a pressure lower than the liquid inlet pressure [126]. Saeed et al. [104] in their research improve the water affinity and mechanical properties of PVAm membranes to enhance $\mathrm{CO}_{2}$ separation at pressures that are moderately high. A PVAm matrix was incorporated with CNC in order to get results that are beneficial. The composite membrane used for $\mathrm{CO}_{2}$ permeation testing was specially designed with ability to work at moderately high pressure under humid conditions.

\section{Membrane Reusability and Capture Efficiency}

Membrane fouling is highly dependent on the membrane material, its structure, and the properties of the filtered suspension. This is considered more serious if the streams contain solid particles, such as traces of fly ash in the gas [127]. In comparison to membrane wetting, membrane fouling effect on performance is however less significant. Alharthi et al. studied the effect of fly ash in flue gas flow [128], and the results of studies show that the influence of fly ash on membrane performance is inconsequential compared to moisture presence in the gas stream. It was reported that moisture can cause a significant decrease in permeability, while exposure to dry fly ash only slightly increases the pressure drop across the membrane. In addition to high sorption capacity, sorbents with excellent regenerability (recoverability) are technically and economically preferred to go through various adsorption/ desorption cycles. In general, by controlling fluctuations in pressure or temperature, regeneration of absorbents can be achieved. The temperature change process can be used to check the suitability of the materials to be treated during $\mathrm{CO}_{2}$ sorption/desorption and also used to regenerate sorbents.

$\mathrm{Li}$ et al. [86] studied the $\mathrm{CO}_{2}$ recyclability of magnetic nanocomposites and observed a slight drop in the $\mathrm{CO}_{2}$ sorption capacity compared to the initial capacity. In general, the excellent regenerability of PEI-magnetic nanocomposites can be explained by the low volatile nature of PEI, good thermal stability, and excellent interaction between PEI and magnetic nanocomposites, $[129,130]$. Yuan et al. [131] defined capture rate as the fraction of the $\mathrm{CO}_{2}$ amount captured from the feed stream. In practice, the capture rate can be zero, which corresponds to the membrane unit bypass scenario. This assumption would not be numerically practical for a given set of mass balance equations for a membrane. Parametric studies have shown that moderate selectivity and high permeability are desirable properties of the capture membrane after combustion [132]. The performance, reusability, and efficiency of nanocomposite membranes can also be improved by introducing dehydration unit or process to ensure that only dried flue gas fed to the membranes (Figure 5).

\section{Significant and Scalable Strategy}

Different membrane types have been developed for specific industrial applications yet cannot come around owing to setbacks arising in scale-up of such membranes to modular configurations which is a very challenging task. In the membrane stage process, there are many variables to consider, such as feed conditions, form pressure at feed and permeate, process design, and driving force strategy. $\mathrm{Nu}-$ merous articles have presented the effects of these variables and have suggested configurations that are useful based on optimization and parametric studies [133, 134]. Sandru et al. [135] developed a pilot scale membrane assembly with fixed carrier separation layers. The flue gas fed to the membrane unit contained $\mathrm{CO}_{2}(12 \%) \mathrm{O}_{2}(6 \%)$, approximately $200 \mathrm{mg} /$ $\mathrm{m}^{3}$ of $\mathrm{NO}_{x}$ and $\mathrm{SO}_{2}$. The permeability values obtained for $\mathrm{CO}_{2}$ were in the range between 0.2 and $0.6 \mathrm{~m}^{3}(\mathrm{STP}) /\left(\mathrm{m}^{2}\right.$ barh), and the selectivity for $\mathrm{CO}_{2} / \mathrm{N}_{2}$ was in the range between 80 and 300. Choi et al. [136] launched a pilotmembrane separation system connected to a liquefied natural gas boiler. The hollow fiber membrane module separation layers were polyethersulfone, and the modules were initially tested with a model $\mathrm{CO}_{2} / \mathrm{N}_{2}$ mixture. The membrane separation was divided into four stages. The permeability to $\mathrm{CO}_{2}$ through the membrane used reaches 40 GPU. Under these operating conditions, $90 \%$ of the $\mathrm{CO}_{2}$ was captured with a purity of $99 \%$. 


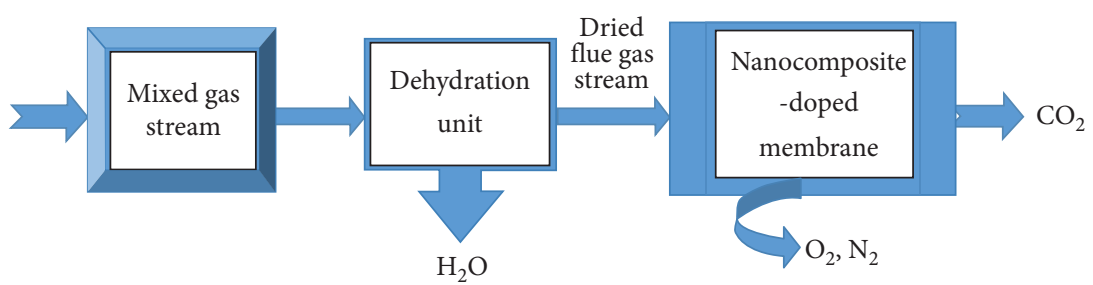

FIGURE 5: Flow diagram for proposed nanocomposite-doped membrane separation process.

Yuan et al. [131] highlight two key properties of the membrane that have a direct effect on the energy and mass balance during the separation process, and they are $\mathrm{CO}_{2}$ permeability and $\mathrm{CO}_{2} / \mathrm{N}_{2}$ selectivity. The permeability is determined by the gas permeability of the membrane and defined as the average permeability over the thickness of the membrane. Membrane selectivity is the ability to penetrate one species over another (that is, ratio of permeabilities of the two species). Huang et al. [137] highlighted that the area of the membrane required for a specific separation objective decreases with increasing permeability for more permeable gases. On the contrary, the desired membrane area increases with increasing selectivity. A larger membrane area is required as selectivity increases so that a positive pressure difference is maintained between the feed and permeate sides by the less permeable gases. A majority of the membranes applied in $\mathrm{CO}_{2}$ capture are still at the laboratory stage of development and testing. However, several membranes have been developed and tested at a pilot scale level by many companies and a few applied for use in full-scale capacity [138]. The application of membrane technology in $\mathrm{CO}_{2}$ capture is currently a technologically feasible and yet small-scale industrial practice worldwide.

However, due to certain economic constraints, there is still uncertainty about how easy it is to use membranes in certain industries. The $\mathrm{CO}_{2}$ capture system designed in a laboratory scale could be scaled up, but some of the challenges for large-scale membrane application in $\mathrm{CO}_{2}$ capture are due to high membrane manufacturing cost for large-scale applications, lack of incentives, and membrane performance affected by operating conditions such as temperature and pressure [138]. Researchers have developed and tested some membranes for their potential in large-scale industrial applicability. Polymeric membranes such as Polyactive ${ }^{\circledR}$ and Polaris ${ }^{\mathrm{TM}}$ are now commercially available. They are operated at lower temperatures and have good thermal and mechanical strength. Table 2 shows that Memfo group at the NTNU developed a flat sheet fixed site carrier membrane which showed stable performance for six months when tested on a pilot scale by EDP power plant in Sines (Portugal) [139]. The Poly Active ${ }^{\mathrm{TM}}$ membranes developed by Helmholtz-Zentrum Geesthacht have been tested on a pilot scale with a $12.5 \mathrm{~m}^{2}$ membrane area to capture $\mathrm{CO}_{2}$ in real flue gas [140].

Lin et al. [141] evaluated Polaris TM thin film composite membrane for $\mathrm{CO}_{2}$ separation from syngas. The membrane system processed about $227 \mathrm{~kg} / \mathrm{h}$ of syngas and reported $95 \%$ of liquid $\mathrm{CO}_{2}$ produced. Possible design variables in scaling membrane activities are the permeability and selectivity of the membrane, surface area of the membrane, and performance of vacuum pumps, compressors, expansion valves, and heat exchangers. The scalability and significant of the design variables are based on their effect on the objective function.

From this study, it was observed that both nanocomposite- and hybrid nanocomposite-doped membranes have not been extensively applied at the industrial scale.

The balance and optimization of some parameters such as the purity requirements, compressor cost, gas rejection specifications, and gas flowrates that are highly processspecific are required for the design of a membrane. Aside from permeability/selectivity trade-off, there are other challenges such as membrane aging that significantly affect the membrane industrial viability [142]. Membrane aging slows over time because the driving force for physical aging is gradually decreased by the presence of excess free volume. Thus, the aging of the membrane will lead to a decrease in gas permeability and a change in other physical properties, which depend on the thickness of the membrane [143]. There are many ways to configure these membranes, but the number of membrane modules, compressors, and the configuration of these systems usually depend on the flow rate desired. Polymer membranes over the last three decades have developed into a feasible gas separation industrial process. During this time, several polymers have been identified as conventional gas separation membranes. Polysulfone is one of the most heat-resistant and chemically stable thermoplastic polymers. Thus, due to its excellent mechanical properties, it is an important industrial membrane material for gas separation [144]. In addition, aromatic polyimide has high intrinsic selectivity and high gas permeability combined with desired physical properties that makes them attractive membrane materials for various gas separation applications. Thermally rearranged polymer is another promising highperformance membrane material for gas separations [145].

As membrane technology research continues to grow, the range of applications also expands. However, in the case of olefin/paraffin separation, finding an actual polymeric material of high performance that will operate under practical feed condition is essential [146]. Economical study by Peters et al. [147] and He et al. [148] to compare the membrane technology with amine scrubbing for natural gas purification of gas feed containing up to $10 \mathrm{~mol} \%$ of $\mathrm{CO}_{2}$ showed that amine scrubbing can be replaced by membranes for gas feeds containing $10 \mathrm{~mol} \% \mathrm{CO}_{2}$ and lower.

\section{Application and Compatibility}

The membrane technology is highly flexible for applications in industries, as it can be used both before and after combustion. The main setback for postcombustion 
TABLE 2: Summary of pilot and industrial scale used membrane.

\begin{tabular}{|c|c|c|c|c|c|c|c|}
\hline Membrane & Industry applied & Scale & $\begin{array}{c}\mathrm{CO}_{2} \text { purity } \\
(\%)\end{array}$ & $\begin{array}{l}\text { Membrane } \\
\text { surface area }\end{array}$ & $\begin{array}{l}\text { Duration of } \\
\text { application }\end{array}$ & $\begin{array}{l}\text { No. of } \\
\text { stages }\end{array}$ & Reference \\
\hline Flat sheet FSC membrane & Cement plant & Pilot & 70 & $18 \mathrm{~m}^{2}$ & 6 months & 2 stages & {$[106]$} \\
\hline Polyactive $^{\mathrm{TM}}$ & Coal-fired power plant & Pilot & $60-70$ & $12.5 \mathrm{~m}^{2}$ & $740 \mathrm{~h}$ & 1 stage & {$[107]$} \\
\hline $\begin{array}{l}\text { Polyethersulphone (PES) } \\
\text { hollow fiber }\end{array}$ & LNG fired flue gas plant & Pilot & 90 & $(2 \mathrm{in}, 3$ in $)$ & & 4 stages & {$[76]$} \\
\hline $\begin{array}{l}\text { Polaris polymeric } \\
\text { FSC membrane }\end{array}$ & Cement plant & Large & 99 & $\begin{array}{l}94400 \mathrm{~m}^{2} \\
41300 \mathrm{~m}^{2} \\
10300 \mathrm{~m}^{2}\end{array}$ & & $\begin{array}{c}2-3 \\
\text { stages }\end{array}$ & {$[28]$} \\
\hline Polaris membrane & $\begin{array}{c}\text { Natural gas } \\
\text { combined-cycle power } \\
\text { plant }\end{array}$ & Pilot & 90 & 8 in diameter & $1000 \mathrm{~h}$ & 2 stages & {$[35]$} \\
\hline FCE electrochemical membrane & PC flue gas power plant & Large & 90 & $11.7 \mathrm{~m}^{2}$ & 9 months & 1 stage & {$[34]$} \\
\hline $\begin{array}{l}\text { Nanoporous superhydrophobic } \\
\text { membrane contactor }\end{array}$ & Coal-fired plant & Pilot & $\begin{array}{c}93.2 \\
2580 \mathrm{GPU}\end{array}$ & $3161 \mathrm{~cm}^{2}$ & & 1 stage & {$[42]$} \\
\hline Polaris $^{\mathrm{TM}}$ & Coal gas power plant & $\begin{array}{c}\text { Lab } \\
\text { Pilot } \\
\text { Large } \\
\end{array}$ & 95 & $\begin{array}{l}30 \mathrm{~cm}^{2} \\
1-4 \mathrm{~m}^{2} \\
20 \mathrm{~m}^{2} \\
\end{array}$ & $2000 \mathrm{~h}$ & 2 stages & {$[33]$} \\
\hline DOW nanofiltration membrane & $\begin{array}{c}\text { Flue gas lignified power } \\
\text { plant }\end{array}$ & Pilot & $764 \mathrm{GPU}$ & $\begin{array}{l}7.5 \mathrm{~m}^{2} \\
5 \mathrm{~m}^{2}\end{array}$ & $\begin{array}{c}5 \mathrm{~h} \\
20 \mathrm{~h}\end{array}$ & 1 stage & {$[90]$} \\
\hline
\end{tabular}

separation is the high selectivity requirement to recuperate relatively low $\mathrm{CO}_{2}$ concentrations from flue gases [149]. Therefore, the development of a membrane separation system that is suitable is very important to meet IEA requirements. Hence, a major challenge in the commercialization of this process is the low selectivity, and since selectivity is important, membrane properties such as porosity, pore size, and wettability also play a vital role in separation efficiency of carbon dioxide [150]. Although the membrane acts only as a supplier of the mass transfer surface, it has a significant impact on the performance of the process. Since all mass exchange occurs in the pores of the membrane, pore size and porosity have a large impact on performance [151]. Membrane can be a composite polymer wherein the cover layer is a thick selective layer clung to a cheap nonselective membrane. The partial pressure between the feed stream and the permeate area functions as a driving mechanism for the permeation of gases through the membrane [152]. The principle issue with permeation technology is the compromise among selectivity and penetrability. Indeed, this restricts the wide utilization of polymeric membranes for carbon capture before combustion because of their low $\mathrm{H}_{2} / \mathrm{CO}_{2}$ selectivity [153].

Industrial applications of $\mathrm{CO}_{2}$ separation membranes require reliable test conditions. The membranes used to capture $\mathrm{CO}_{2}$ prior to combustion and removal of sulfur from natural gas require high-pressure conditions. However, $\mathrm{CO}_{2}$ separation before and after combustion requires hightemperature operations. It is also important to conduct research at a high operating pressure because of the condensable nature of $\mathrm{CO}_{2}$, and at a higher operating pressure, adsorption of $\mathrm{CO}_{2}$ begins to plasticize the membrane, which leads to a decrease in membrane selectivity [121]. Physical aging is a thermodynamic phenomenon that manifests itself, especially in polymers with low chain packing, due to relaxation and convergence of chains, which leads to a decrease in the fraction of the free volume of the membrane. The performance of nanodoped membrane can further be improved through the development of multifunctional thermal and chemical resistance composite materials, whereby the unique properties of the nanocomposite may be combined to surface reactive moieties, leading to other activities [154]. The number of commercial membranes that can be used to separate carbon dioxide after postcombustion is limited. Most of the commercial membranes have been tested in coal-fired power plants [44].

White et al. [155] applied a pilot-membrane sized system to separate a flue gas stream that contained about a ton of $\mathrm{CO}_{2}$ /day corresponding to approximately $0.05 \mathrm{MWe}$ of a carbon source fired power plant. The technological design is made use of a two-step separation process. It first used in the first stage a combination of light feed compression and permeate vacuum to achieve a pressure and capture ratio of approximately $50 \%$ of $\mathrm{CO}_{2}$ in the inlet gas stream. The second step used combustion air as a purge gas to increase $\mathrm{CO}_{2}$ recovery to about $90 \%$. Pohlmann et al. [140] used simulation results published by Brinkmann et al. [156] to develop a pilot scale unit consisting of envelope modules containing separation layers, with effective membrane area of about $13 \mathrm{~m}^{2}$. Flue gas stream containing $14.6 \% \mathrm{CO}_{2}, 6.7 \%$ $\mathrm{O}_{2}, 51-100$ ppm $\mathrm{SO}_{2}, 75-91$ ppm $\mathrm{NO}_{x}$, and $14.5 \%$ of $\mathrm{H}_{2} \mathrm{O}$ was used, while the input and permeate pressures were 1.265 and 0.05 bar, respectively. The authors highlighted the need to pretreat the gas stream before entering the membrane. This pretreatment stage includes removal of condensates, water vapour, and dust from the gas stream. There are several factors that can affect a membrane performance in a gas permeation process, they include, but are not limited to, changes in feedstock composition which affect directly the adsorption phenomenon or the swelling degree at the gas film interface as envisage by sorption/diffusion principles. Since the diffusion of gas components in the membrane 
depends on the concentration or solubility of the components, feed stock composition greatly influences the permeation properties. Interaction effects between two or more species can occur in multicomponent feeds, which can greatly affect selectivity [157].

Carbon capture and storage involves $\mathrm{CO}_{2}$ separation from energy-related industrial sources, transportation to storage sites, and long-term segregation from the atmosphere. The isolated carbon dioxide can then undergo compression and transported to suitable storage sites such as in geological formations, oceans, carbonate minerals, and oil and gas reservoirs, or used in industrial processes. $\mathrm{CO}_{2}$ stockpiling plays an important role in the CCS chain and falls into two distinct categories: collection using geological infrastructure and marine base infrastructure. Geological infrastructure includes coal reserves, gas fields, oil fields, groundwater production, and sedimentary and fresh water resources [158]. The choice will depend on technology maturity, cost, diffusion, overall capacity, and technology transfer. Thus, potential technical storage of $\mathrm{CO}_{2}$ includes ocean storage, geological storage, and industrial conversion of $\mathrm{CO}_{2}$ to inorganic carbonates [159]. For geological storage, essential physical trapping mechanism such as caprock is necessary, in order to prevent $\mathrm{CO}_{2}$ from migrating to the surface. The potential for industrial use of $\mathrm{CO}_{2}$ is low, and there is relatively little experience in the literature with combining $\mathrm{CO}_{2}$ capture, transport, and storage into a fully integrated CCS system [160]. Although the geological storage seems to be a more reliable method for large storage of $\mathrm{CO}_{2}$, however, the orientation of both the formation pores and mineral grains or fracture along a preferential direction can also constitute barriers to flow resulting in different elastic response. Therefore, quantifying geological heterogeneity will affect the challenges of deploying large-scale carbon dioxide storage facilities in geological formations, which will affect microscopic fluid displacement and tire integrity [161]. $\mathrm{CO}_{2}$ is also used in greenhouses to improve plant growth. Today, many companies are developing new ways to use capture $\mathrm{CO}_{2}$, including its use for the enhancement of concrete, chemicals and fuels, polymers for plastics, carbon fiber, and carbon materials.

The efficiency of the membrane gas separation process largely depends on the transport characteristics of the membrane, that is, its permeability and selectivity in relation to specific gases in the mixture. Materials used or used for gas separation membranes cover the entire spectrum of organic and inorganic substances, from polymers to ceramics, metals, and other inorganic materials on the one hand [162]. Inorganic membranes generally exhibit better mechanical, chemical, pressure, and thermal stability compared to other polymer membranes.

\section{Considerations for Future Research}

(1) Evaluating of the Knudsen diffusion mechanism in membranes by using knowledge-based systems, developed from artificial intelligence techniques to improve performance and carbon capture efficiency.
(2) Application of smart models in simulating steady state process associated with membranes selectivity and permeability trends in carbon capture.

(3) Identifying optimal and appropriate nanomaterials/ particles for low-cost membrane fabrication and doping.

(4) Application of less dense hybrid nanocomposites that will avoid membrane poisoning and increase membrane performance in terms of selectivity and permeability.

(5) Doping phase incompatibility and morphological defects should be considered in developing novel nanohybrid particles/materials for membrane doping (that is, optimizing compatibility between the different constituent composites).

(6) Development of hybrid nanocomposites that can break the permeability-selectivity trade-off for practical carbon capture and gas separation.

(7) The effect of physical aging on long-term polymericbased membrane doped with nanocomposites should be evaluated.

\section{Conclusion}

Different membrane materials have different separation characteristic properties, thermal and chemical stabilities, mechanical strengths, and costs of production, and they have their different own suitable uses. Carbon capture with gas separation membranes has attracted great interest over the last ten years; however, there are still problems associated with postcombustion $\mathrm{CO}_{2}$ capture membranes, such as limited membrane separation performance (with most polymer membranes, there is a trade-off between permeability and selectivity), membrane stability, and durability. Therefore, the membranes for carbon capture applications must be specifically developed with high performance and relatively low manufacturing costs. The choice of a suitable membrane material for a particular application depends primarily on the properties of the membrane material, the composition/impurities of the feed gas, the operating conditions of the process, and the separation requirements. Recently, the efficiency of membrane separation has been greatly improved due to the great efforts of researchers.

From this study, it was observed that both nanocomposite- and hybrid nanocomposite-doped membranes have not been extensively applied on the industrial scale. Some critiques indicate that hybrid nanocomposites commonly used in membrane manufacturing have high intrinsic costs for their raw materials and manufacturing technologies. Thus, more research is still needed to reduce the cost of hybrid nanocomposites and identify new hybrid nanocomposites at lower manufacturing costs.

\section{Data Availability}

No data were used to support the findings of this study. 


\section{Conflicts of Interest}

The authors have no conflicts of interest regarding the publication of this manuscript.

\section{Acknowledgments}

The authors appreciate the management of Covenant University for the support in making this publication a reality.

\section{References}

[1] World Meteorological Organization, WMO Greenhouse Gas Bulletin No. 10, World Meteorological Organization, Geneva, Switzerland, 2014.

[2] Energy Information Administration (EIA), Annual Energy Outlook, Energy Information Administration (EIA), Washington, DC, USA, 2014.

[3] P. Markewitz, W. Kuckshinrichs, W. Leitner et al., "Worldwide innovations in the development of carbon capture technologies and the utilization of $\mathrm{CO}_{2}$," Energy \& Environmental Science, vol. 5, no. 6, pp. 7281-7305, 2012.

[4] Z. H. Lee, K. T. Lee, S. Bhatia, and A. R. Mohamed, "Postcombustion carbon dioxide capture: evolution towards utilization of nanomaterials," Renewable and Sustainable Energy Reviews, vol. 16, no. 5, pp. 2599-2609, 2012.

[5] S. Shang, A. Hanif, M. Sun et al., "Novel M (Mg/Ni/Cu)-Al$\mathrm{CO}_{3}$ layered double hydroxides synthesized by aqueous miscible organic solvent treatment (AMOST) method for $\mathrm{CO}_{2}$ capture," Journal of Hazardous Materials, vol. 373, pp. 285-293, 2019.

[6] R. Kumar, R. Mangalapuri, M. Ahmadi et al., "The role of nanotechnology on post-combustion $\mathrm{CO}_{2}$ absorption in process industries," International Journal of Low-Carbon Technologies, vol. 15, no. 3, pp. 361-367, 2020.

[7] I. Sreedhar, R. Vaidhiswaran, B. M. Kamani, and A. Venugopal, "Process and engineering trends in membrane based carbon capture," Renewable and Sustainable Energy Reviews, vol. 68, pp. 659-684, 2017.

[8] R. M. Cuéllar-Franca and A. Azapagic, "Carbon capture, storage and utilisation technologies: a critical analysis and comparison of their life cycle environmental impacts," Journal of $\mathrm{CO}_{2}$ Utilization, vol. 9, pp. 82-102, 2015.

[9] Z. Zhang, J. Cai, F. Chen, H. Li, W. Zhang, and W. Qi, "Progress in enhancement of $\mathrm{CO}_{2}$ absorption by nanofluids: a mini review of mechanisms and current status," Renewable Energy, vol. 118, pp. 527-535, 2018.

[10] T. C. Merkel, H. Lin, X. Wei, and R. Baker, "Power plant post-combustion carbon dioxide capture: an opportunity for membranes," Journal of Membrane Science, vol. 359, no. 1-2, pp. 126-139, 2010.

[11] M. Saeed and L. Deng, "Carbon nanotube enhanced PVAmimic enzyme membrane for post-combustion CO 2 capture," International Journal of Greenhouse Gas Control, vol. 53, pp. 254-262, 2016.

[12] N. Bhoria, J. Pokhrel, S. Anastasiou et al., "Composite porous nanostructures as multi-action adsorbents and membrane fillers for carbon dioxide separation: comparative performance of metal organic framework-graphene oxide hybrids," Materials Today: Proceedings, vol. 37, pp. 4044-4048, 2021.

[13] W. Yan, Z. Wang, S. Zhao, J. Wang, P. Zhang, and X. Cao, "Combining co-solvent-optimized interfacial polymerization and protective coating-controlled chlorination for highly permeable reverse osmosis membranes with high rejection," Journal of Membrane Science, vol. 572, pp. 61-72, 2019.

[14] J. D. Figueroa, T. Fout, S. Plasynski, H. McIlvried, and R. D. Srivastava, "Advances in $\mathrm{CO}_{2}$ capture technology-the U.S. department of energy's carbon sequestration program," International Journal of Greenhouse Gas Control, vol. 2, no. 1, pp. 9-20, 2008.

[15] C. Stewart and M.-A. Hessami, "A study of methods of carbon dioxide capture and sequestration - the sustainability of a photosynthetic bioreactor approach," Energy Conversion and Management, vol. 46, no. 3, pp. 403-420, 2005.

[16] G. Bagnato and A. Sanna, Carbon dioxide separation/capture by using membranes, in Chapter 15 Current Trends and Future Developments on (Bio-) Membranes, pp. 415-435, Elsevier, Amsterdam, Netherlands, 2018.

[17] M. Tambe, M. M. Maroto-Valer, and A. J. Finn, "Study of design parameters affecting the performance of $\mathrm{CO}_{2}$ purification units in oxyfuel combustion," International Journal of Greenhouse Gas Control, vol. 12, pp. 441-449, 2013.

[18] K. Goto, K. Yogo, and T. Higashii, "A review of efficiency penalty in a coal-fired power plant with post-combustion $\mathrm{CO}_{2}$ capture," Applied Energy, vol. 94, pp. 109-116, 2012.

[19] U. W. R. Siagian, N. F. Himma, K. Khoiruddin, I. G. Wenten, and G. Wenten, "Membrane-based carbon capture technologies: membrane gas separation vs. membrane contactor," Journal of Natural Gas Science and Engineering, vol. 67, pp. 172-195, 2019.

[20] P. Pal, Membrane-Based Technologies for Environmental Pollution Control, pp. 359-368, Butterworth-Heinemann, Oxford, UK, 1st edition, 2020.

[21] G. Ji and M. Zhao, Membrane Separation Technology in Carbon Capture, Recent Advances in Carbon Capture and Storage, Yongseung Yun, IntechOpen, London, UK, 2017, https://www.intechopen.com/books/recent-advances-incarbon-capture-and\%20storage/membrane-separationtechnology-in-carbon-capture.

[22] X. Gu, Z. Tang, and J. Dong, "On-stream modification of MFI zeolite membranes for enhancing hydrogen separation at high temperature," Microporous and Mesoporous Materials, vol. 11, no. 1, pp. 441-448, 2008.

[23] X. He, "A review of material development in the field of carbon capture and the application of membrane-based processes in power plants and energy-intensive industries," Energy, Sustainability and Society, vol. 8, no. 1, p. 34, 2018.

[24] P. Bernardo and E. Drioli, "Membrane gas separation progresses for process intensification strategy in the petrochemical industry," Petroleum Chemistry, vol. 50, no. 4, pp. 271-282, 2010.

[25] M. A. Aroon, A. F. Ismail, T. Matsuura, and M. M. Montazer-Rahmati, "Performance studies of mixed matrix membranes for gas separation: a review," Separation and Purification Technology, vol. 75, no. 3, pp. 229-242, 2010.

[26] W. J. Koros and R. Mahajan, "Pushing the limits on possibilities for large scale gas separation: which strategies?" Journal of Membrane Science, vol. 175, no. 2, pp. 181-196, 2000.

[27] M. Wang, V. Janout, and S. L. Regen, "Gas transport across hyperthin membranes," Accounts of Chemical Research, vol. 46, no. 12, pp. 2743-2754, 2013.

[28] G. George, N. Bhoria, S. AlHallaq, A. Abdala, and V. Mittal, "Polymer membranes for acid gas removal from natural gas," 
Separation and Purification Technology, vol. 158, pp. 333356, 2016.

[29] Z. Shao, G. Xiong, Y. Cong, and W. Yang, "Synthesis and oxygen permeation study of novel perovskite-type $\mathrm{BaBi}_{x} \mathrm{Co}_{0.2} \quad \mathrm{Fe}_{0.8-x} \mathrm{O}_{3-\delta}$ ceramic membranes," Journal of Membrane Science, vol. 164, no. 1-2, pp. 167-176, 2000.

[30] J. Tong, W. Yang, B. Zhu, and R. Cai, "Investigation of ideal zirconium-doped perovskite-type ceramic membrane materials for oxygen separation," Journal of Membrane Science, vol. 203, no. 1-2, pp. 175-189, 2002.

[31] G. He, S. Huang, L. F. Villalobos et al., "High-permeance polymer-functionalized single-layer graphene membranes that surpass the postcombustion carbon capture target," Energy \& Environmental Science, vol. 12, no. 11, pp. 33053312, 2019.

[32] F. Ahmad, K. K. Lau, A. M. Shariff, and Y. Fong Yeong, "Temperature and pressure dependence of membrane permeance and its effect on process economics of hollow fiber gas separation system," Journal of Membrane Science, vol. 430, pp. 44-55, 2013.

[33] D. T. Coker, T. Allen, B. D. Freeman, and G. K. Fleming, "Nonisothermal model for gas separation hollow-fiber membranes," AIChE Journal, vol. 45, no. 7, pp. 1451-1468, 1999.

[34] F. Wang, L. Zhao, P. He, and X. Z. Zhao, "Effect of temperature on oil-gas separation in membrane separation based transformer on-line monitoring," Advanced Materials Research, vol. 211-212, pp. 389-394, 2011.

[35] C. A. Scholes, M. T. Ho, D. E. Wiley, G. W. Stevens, and S. E. Kentish, "Cost competitive membrane-cryogenic postcombustion carbon capture," International Journal of Greenhouse Gas Control, vol. 17, pp. 341-348, 2013.

[36] Y. Han and W. S. W. Ho, "Recent advances in polymeric membranes for $\mathrm{CO}_{2}$ capture," Chinese Journal of Chemical Engineering, vol. 26, no. 11, pp. 2238-2254, 2018.

[37] T. D. Kusworo, D. Qudratun, D. P. Utomo, Indriyanti, and I. R. Ramadhan, "Enhancement of separation performance of nano hybrid $\mathrm{PES}-\mathrm{TiO}_{2}$ membrane using three combination effects of ultraviolet irradiation, ethanol-acetone immersion, and thermal annealing process for $\mathrm{CO}_{2}$ removal," Journal of Environmental Chemical Engineering, vol. 6, no. 2, pp. 2865-2873, 2018.

[38] G. Rusciano, A. C. De Luca, G. Pesce, and A. Sasso, "On the interaction of nano-sized organic carbon particles with model lipid membranes," Carbon, vol. 47, no. 13, pp. 2950-2957, 2009.

[39] Y.-F. Lin, W.-W. Wang, and C.-Y. Chang, "Environmentally sustainable, fluorine-free and waterproof breathable PDMS/ PS nanofibrous membranes for carbon dioxide capture," Journal of Materials Chemistry A, vol. 6, no. 20, pp. 94899497, 2018.

[40] G. Zainab, N. Iqbal, A. A. Babar et al., "Free-standing, spiderweb-like polyamide/carbon nanotube composite nanofibrous membrane impregnated with polyethyleneimine for $\mathrm{CO}_{2}$ capture," Composites Communications, vol. 6, pp. 41-47, 2017.

[41] E. P. Favvas, N. S. Heliopoulos, S. K. Papageorgiou, A. C. Mitropoulos, G. C. Kapantaidakis, and N. K. Kanellopoulos, "Helium and hydrogen selective carbon hollow fiber membranes: the effect of pyrolysis isothermal time," Separation and Purification Technology, vol. 142, pp. 176-181, 2015.

[42] D. Parsley, R. J. Ciora Jr., D. L. Flowers et al., "Field evaluation of carbon molecular sieve membranes for the separation and purification of hydrogen from coal- and biomass-derived syngas," Journal of Membrane Science, vol. 450, pp. 81-92, 2014.

[43] C. Sun, F. Ma, L. Cai et al., "Metal-free ternary BCN nanosheets with synergetic effect of band gap engineering and magnetic properties," Scientific Reports, vol. 7, pp. 6617-6618, 2017.

[44] M. Kárászová, B. Zach, Z. Petrusová et al., "Post-combustion carbon capture by membrane separation, review," Separation and Purification Technology, vol. 238, Article ID 116448, 2020.

[45] Y. Lv, X. Yu, J. Jia, S.-T. Tu, J. Yan, and E. Dahlquist, "Fabrication and characterization of superhydrophobic polypropylene hollow fiber membranes for carbon dioxide absorption," Applied Energy, vol. 90, no. 1, pp. 167-174, 2012.

[46] M. Fosi-Kofal, A. Mustafa, A. F. Ismail, M. Rezaei-DashtArzhandi, and T. Matsuura, "PVDF/ $\mathrm{CaCO}_{3}$ composite hollow fiber membrane for $\mathrm{CO}_{2}$ absorption in gas-liquid membrane contactor," Journal of Natural Gas Science and Engineering, vol. 31, pp. 428-436, 2016.

[47] J. C. Hicks, J. H. Drese, D. J. Fauth, M. L. Gray, G. Qi, and C. W. Jones, "Designing adsorbents for $\mathrm{CO}_{2}$ capture from flue gas-hyperbranched aminosilicas capable of capturing $\mathrm{CO}_{2}$ reversibly," Journal of the American Chemical Society, vol. 130, no. 10, pp. 2902-2903, 2008.

[48] H. Cui, Y. Guo, L. Guo, L. Wang, Z. Zhou, and Z. Peng, "Heteroatom-doped carbon materials and their composites as electrocatalysts for $\mathrm{CO}_{2}$ reduction," Journal of Material Chemistry Series A, vol. 6, pp. 18782-18793, 2018

[49] D. R. Paul and Y. P. Yampol'skii, Polymeric Gas Separation Membranes, CRC Press, Boca Raton, FL, USA, 1994.

[50] K.-M. Kim, J.-W. Lee, and J.-B. Lee, "No-mixing-loss design of a multistage membrane carbon capture process for off-gas in thermal power plants," Journal of Membrane Science, vol. 598, Article ID 117796, 2020.

[51] Y. Ding, "Perspective on gas separation membrane materials from process economics point of view," Industrial \& Engineering Chemistry Research, vol. 59, no. 2, pp. 556-568, 2020.

[52] M. Galizia, W. S. Chi, Z. P. Smith, T. C. Merkel, R. W. Baker, and B. D. Freeman, "50th anniversary perspective: polymers and mixed matrix membranes for gas and vapor separation: a review and prospective opportunities," Macromolecules, vol. 50, no. 20, pp. 7809-7843, 2017.

[53] P. Kundu, R. Zakaria, A. Chakma, and X. Feng, "Analysis of permeate pressure build-up effects on separation performance of asymmetric hollow fiber membranes," Chemical Engineering Science, vol. 104, pp. 849-856, 2013.

[54] J. Hao, P. A. Rice, and S. A. Stern, "Upgrading low-quality natural gas with $\mathrm{H}_{2} \mathrm{~S}$ - and $\mathrm{CO}_{2}$-selective polymer membranes," Journal of Membrane Science, vol. 320, no. 1-2, pp. 108-122, 2008.

[55] S. Luo, K. A. Stevens, J. S. Park et al., "Highly $\mathrm{CO}_{2}$-selective gas separation membranes based on segmented copolymers of poly(ethylene oxide) reinforced with pentiptycene-containing polyimide hard segments," ACS Applied Materials \& Interfaces, vol. 8, no. 3, pp. 2306-2317.

[56] C. H. Lau, P. Li, F. Li, T.-S. Chung, and D. R. Paul, "Reverseselective polymeric membranes for gas separations," Progress in Polymer Science, vol. 38, no. 5, pp. 740-766, 2013.

[57] C. feng, R. Wang, H. Zhang, and L. Shi, "Diverse morphologies of pvdf hollow fiber membranes and their performance analysis as gas/liquid contactors," Journal of Applied Polymer Science, vol. 119, no. 3, pp. 1259-1267, 2011. 
[58] S. Alexander Stern, "Polymers for gas separations: the next decade," Journal of Membrane Science, vol. 94, no. 1, pp. 1-65, 1994.

[59] H. P. Hsieh, "Chapter 1: membranes and membrane processes," in Inorganic Membranes for Separation and Reaction, pp. 1-13, Elsevier, Amsterdam, Netherlands, 1996.

[60] A. J. Burggraaf and K. Keizer, "Synthesis of inorganic membranes," in Inorganic Membranes: Synthesis, Characteristics, and Applications, R. R. Bhave, Ed., Van Nostrand Reinhold, New York, NY, USA, pp. 10-63, 1991.

[61] M. H. Hassan, J. Douglas Way, P. M. Thoen, and A. C. Dillon, "Single component and mixed gas transport in a silica hollow fiber membrane," Journal of Membrane Science, vol. 104, no. 1-2, pp. 27-42, 1995.

[62] D. Shekhawat, D. R. Luebke, and H. W. Pennline, "A review of carbon dioxide selective membranes: a topical report," 2003.

[63] J. Caro, M. Noack, P. Kölsch, and R. Schäfer, "Zeolite membranes-state of their development and perspective," Microporous and Mesoporous Materials, vol. 38, no. 1, pp. 3-24, 2000.

[64] C. Joly, M. Smaihi, L. Porcar, and R. D. Noble, "Polyimide-Silica composite materials: how does silica influence their microstructure and gas permeation properties?" Chemistry of Materials, vol. 11, no. 9, pp. 2331-2338, 1999.

[65] D. Li and S.-T. Hwang, "Preparation and characterization of silicon based inorganic membrane for gas separation," Journal of Membrane Science, vol. 59, no. 3, pp. 331-352, 1991.

[66] O. Kedem, "The role of coupling in pervaporation," Journal of Membrane Science, vol. 47, 1989.

[67] C. Chen, B. Han, J. Li, T. Shang, J. Zou, and W. Jiang, "A new model on the diffusion of small molecule penetrants in dense polymer membranes," Journal of Membrane Science, vol. 187, no. 1-2, pp. 109-118, 2001.

[68] R. J. R. Uhlhorn, K. Keizer, and A. J. Burggraaf, "Gas and surface diffusion in modified $\gamma$-alumina systems," Journal of Membrane Science, vol. 46, no. 2-3, pp. 225-241, 1989.

[69] Y.-K. Cho, K. Han, and K.-H. Lee, "Separation of $\mathrm{CO}_{2}$ by modified $\gamma-\mathrm{Al}_{2} \mathrm{O}_{3}$ membranes at high temperature," Journal of Membrane Science, vol. 104, no. 3, pp. 219-230, 1995.

[70] K. Kusakabe, T. Kuroda, A. Murata, and S. Morooka, "formation of a Y-type zeolite membrane on a porous $\alpha$-alumina tube for gas separation," Industrial \& Engineering Chemistry Research, vol. 36, no. 3, pp. 649-655, 1997.

[71] S. A. Stern, V. M. Shah, and B. J. Hardy, "Structure-permeability relationships in silicone polymers," Journal of Polymer Science Part B: Polymer Physics, vol. 25, no. 6, pp. 1263-1298, 1987.

[72] Q. Zhu, X. Tang, S. Feng, Z. Zhong, J. Yao, and Z. Yao, “ZIF$8 @ \mathrm{SiO}_{2}$ composite nanofiber membrane with bioinspired spider web-like structure for efficient air pollution control," Journal of Membrane Science, vol. 581, pp. 252-261, 2019.

[73] C. Wang, Y. Liang, J. Miao et al., "Preparation and properties of polyvinyl alcohol (PVA)/mesoporous silica supported phosphotungstic acid (MS-HPW) hybrid membranes for alkali recovery," Journal of Membrane Science, vol. 592, Article ID 117388, 2019.

[74] Z. Gao, R. Fan, J. Ralston, W. Sun, and Y. Hu, "Surface broken bonds: an efficient way to assess the surface behaviour of fluorite," Minerals Engineering, vol. 130, pp. 1523, 2019.

[75] R. Al-Attabi, L. F. Dumée, J. A. Schütz, and Y. Morsi, "Pore engineering towards highly efficient electrospun nanofibrous membranes for aerosol particle removal," Science of the Total Environment, vol. 625, pp. 706-715, 2018.

[76] S. Ghosh and S. Ramaprabhu, "Boron and nitrogen co-doped carbon nanosheets encapsulating nano iron as an efficient catalyst for electrochemical $\mathrm{CO}_{2}$ reduction utilizing a proton exchange membrane $\mathrm{CO}_{2}$ conversion cell," Journal of Colloid and Interface Science, vol. 559, pp. 169-177, 2020.

[77] Q. Song, S. K. Nataraj, M. V. Roussenova et al., "Zeolitic imidazolate framework (ZIF-8) based polymer nanocomposite membranes for gas separation," Energy \& Environmental Science, vol. 5, no. 8, pp. 8359-8369, 2012.

[78] Y. Liu, H. Wu, L. Min et al., "2D layered double hydroxide membranes with intrinsic breathing effect toward $\mathrm{CO}_{2}$ for efficient carbon capture," Journal of Membrane Science, vol. 598, Article ID 117663, 2020.

[79] X.-Y. Chi, P.-Y. Zhang, X.-J. Guo, and Z.-L. Xu, "A novel TFC forward osmosis (FO) membrane supported by polyimide (PI) microporous nanofiber membrane," Applied Surface Science, vol. 427, pp. 1-9, 2018.

[80] H. K. Melvin Ng, C. P. Leo, and A. Z. Abdullah, "Selective removal of dyes by molecular imprinted $\mathrm{TiO}_{2}$ nanoparticles in polysulfone ultrafiltration membrane," Journal of Environmental Chemical Engineering, vol. 5, no. 4, pp. 3991-3998, 2017.

[81] T. Arumugham, R. G. Amimodu, N. J. Kaleekkal, and D. Rana, "Nano $\mathrm{CuO} / \mathrm{g}-\mathrm{C}_{3} \mathrm{~N}_{4}$ sheets-based ultrafiltration membrane with enhanced interfacial affinity, antifouling and protein separation performances for water treatment application," Journal of Environmental Sciences, vol. 82, pp. 57-69, 2019.

[82] P. Bernardo, E. Drioli, and G. Golemme, "Membrane gas separation: a review/state of the art," Industrial \& Engineering Chemistry Research, vol. 48, no. 10, pp. 4638-4663, 2009.

[83] P. Sun, K. Wang, and H. Zhu, "Recent developments in graphene-based membranes: structure, mass-transport mechanism and potential applications," Advanced Materials, vol. 28, no. 12, pp. 2287-2310, 2016.

[84] H. Julian, Polysulfone Mixed Matrix Membrane for $\mathrm{CO}_{2} / \mathrm{N}_{2}$ Separation, Teknik Kimia Institut Teknologi Bandung, Bandung, Indonesia, 2020.

[85] X. Li, J. E. Remias, J. K. Neathery, and K. Liu, "NF/RO faujasite zeolite membrane-ammonia absorption solvent hybrid system for potential post-combustion $\mathrm{CO}_{2}$ capture application," Journal of Membrane Science, vol. 366, no. 1-2, pp. 220-228, 2011.

[86] X. Wu, W. Liu, H. Wu et al., "Nanoporous ZIF-67 embedded polymers of intrinsic microporosity membranes with enhanced gas separation performance," Journal of Membrane Science, vol. 548, pp. 309-318, 2018.

[87] W. Li, J. Wu, S. S. Lee, and J. D. Fortner, "Surface tunable magnetic nano-sorbents for carbon dioxide sorption and separation," Chemical Engineering Journal, vol. 313, pp. 1160-1167, 2017.

[88] Y. Wu, Z. Guo, H. Wu et al., "Plasticization- and agingresistant membranes with venation-like architecture for efficient carbon capture," Journal of Membrane Science, vol. 609, Article ID 118215, 2020.

[89] R. W. Baker and B. T. Low, "Gas separation membrane materials: a perspective," Macromolecules, vol. 47, no. 20, pp. 6999-7013, 2014.

[90] J. G. Wijmans and R. W. J. Baker, "The solution-diffusion model: a review," Journal of Membrane Science, vol. 107, no. 1-2, pp. 1-21, 1995. 
[91] W. K. Son, J. H. Youk, T. S. Lee, and W. H. Park, "Electrospinning of ultrafine cellulose acetate fibers: studies of a new solvent system and deacetylation of ultrafine cellulose acetate fibers," Journal of Polymer Science Part B: Polymer Physics, vol. 42, no. 1, pp. 5-11, 2004.

[92] S. Kononova, G. Gubanova, E. Korytkova et al., "Polymer nanocomposite membranes," Applied Sciences, vol. 8, no. 7, p. 1181, 2018.

[93] I. V. Gofman, E. M. Ivan'kova, I. V. Abalov et al., "Effect of nanoparticles of various types as fillers on mechanical properties of block samples of a heat-resistant polyimide material: a comparative analysis," Polymer Science Series A, vol. 58, no. 1, pp. 87-94, 2016.

[94] V. E. Yudin, J. U. Otaigbe, S. Gladchenko et al., "New polyimide nanocomposites based on silicate type nanotubes: dispersion, processing and properties," Polymer, vol. 48, no. 5, pp. 1306-1315, 2007.

[95] S. E. Sanni, O. Agboola, O. Fagbiele, E. O. Yusuf, and M. E. Emetere, "Optimization of natural gas treatment for the removal of $\mathrm{CO}_{2}$ and $\mathrm{H}_{2} \mathrm{~S}$ in a novel alkaline-DEA hybrid scrubber," Egyptian Journal of Petroleum, vol. 29, no. 1, pp. 83-94, 2020.

[96] M. Rezakazemi, M. Sadrzadeh, and T. Matsuura, “Thermally stable polymers for advanced high-performance gas separation membranes," Progress in Energy and Combustion Science, vol. 66, pp. 1-41, 2018.

[97] Q. Wang, J. Luo, Z. Zhong, and A. Borgna, " $\mathrm{CO}_{2}$ capture by solid adsorbents and their applications: current status and new trends," Energy \& Environmental Science, vol. 4, no. 1, pp. $42-55,2011$.

[98] P. Tamilarasan and S. Ramaprabhu, "Polyaniline-magnetite nanocapsules based nanocomposite for carbon dioxide adsorption," International Journal of Greenhouse Gas Control, vol. 10, pp. 486-493, 2012.

[99] Z. Liu, Z. Du, W. Zou, H. Li, J. Mi, and C. Zhang, "Easily collected nano-absorbents for carbon dioxide capture," Chemical Engineering Journal, vol. 223, pp. 915-920, 2013.

[100] C.-H. Yu, C.-H. Huang, and C.-S. Tan, "A review of $\mathrm{CO}_{2}$ capture by absorption and adsorption," Aerosol and Air Quality Research, vol. 12, no. 5, pp. 745-769, 2012.

[101] L. Li, R. Xu, C. Song, B. Zhang, Q. Liu, and T. Wang, "A review on the progress in nanoparticle/C hybrid CMS membranes for gas separation," Membranes, vol. 8, no. 4, p. 134, 2018.

[102] Z. Su, M. Zhang, Z. Lu, S. Song, Y. Zhao, and Y. Hao, "Functionalization of cellulose fiber by in situ growth of zeolitic imidazolate framework-8 (ZIF-8) nanocrystals for preparing a cellulose-based air filter with gas adsorption ability," Cellulose, vol. 25, no. 3, pp. 1997-2008, 2018.

[103] T. Tu, S. Liu, Q. Cui, L. Xu, L. Ji, and S. Yan, "Technoeconomic assessment of waste heat recovery enhancement using multi-channel ceramic membrane in carbon capture process," Chemical Engineering Journal, vol. 400, Article ID 125677, 2020.

[104] U. Saeed, Z. Jahan, M. B. K. Niazi, E. Pervaiz, and F. Sher, "Biogas upgrading with novel cellulose nano-crystals and polyvinyl amine nanocomposite membranes," Polymer Testing, vol. 91, Article ID 106867, 2020.

[105] K. M. Elsabawy and A. M. Fallatah, "Fabrication of ultraperformance non-compact graphene/carbon hollow fibers/ graphene stationary junction like membrane for $\mathrm{CO}_{2}$ capture," Materials Chemistry and Physics, vol. 211, pp. 264-269, 2018.
[106] S. Hasebe, S. Aoyama, M. Tanaka, and H. Kawakami, " $\mathrm{CO}_{2}$ separation of polymer membranes containing silica nanoparticles with gas permeable nano-space," Journal of Membrane Science, vol. 536, pp. 148-155, 2017.

[107] L. Cheng, Y. Song, H. Chen, G. Liu, G. Liu, and W. Jin, "g$\mathrm{C}_{3} \mathrm{~N}_{4}$ nanosheets with tunable affinity and sieving effect endowing polymeric membranes with enhanced $\mathrm{CO}_{2}$ capture property," Separation and Purification Technology, vol. 250, Article ID 117200, 2020.

[108] W. Shang, F. Sun, W. Jia et al., "High-performance nanofiltration membrane structured with enhanced stripe nanomorphology," Journal of Membrane Science, vol. 600, Article ID 117852, 2020.

[109] X. Wu, Z. Tian, S. Wang et al., "Mixed matrix membranes comprising polymers of intrinsic microporosity and covalent organic framework for gas separation," Journal of Membrane Science, vol. 528, pp. 273-283, 2017.

[110] T.-S. Chung, Y. Li, and S. Kulprathipanja, "Mixed matrix membranes (MMMs) comprising organic polymers with dispersed inorganic fillers for gas separation," Progress in Polymer Science, vol. 32, no. 4, pp. 483-507, 2007.

[111] M. Rezakazemi, A. Ebadi Amooghin, M. M. MontazerRahmati, A. F. Ismail, and T. Matsuura, "State-of-the-art membrane based $\mathrm{CO}_{2}$ separation using mixed matrix membranes (MMMs): an overview on current status and future directions," Progress in Polymer Science, vol. 39, no. 5, pp. 817-861, 2014.

[112] H. Zou, F. Yi, M. Song et al., "Novel synthesis of $\mathrm{Bi}^{-} \mathrm{Bi}_{2} \mathrm{O}_{3}$ $\mathrm{TiO}_{2}-\mathrm{C}$ composite for capturing iodine-129 in off-gas," Journal of Hazardous Materials, vol. 365, pp. 81-87, 2019.

[113] J. Ahn, W.-J. Chung, I. Pinnau, and M. D. Guiver, "Polysulfone/silica nanoparticle mixed-matrix membranes for gas separation," Journal of Membrane Science, vol. 314, no. 1-2, pp. 123-133, 2008.

[114] M. S. Suleman, K. K. Lau, and Y. F. Yeong, "Plasticization and swelling in polymeric membranes in $\mathrm{CO}_{2}$ removal from natural gas," Chemical Engineering Technology, vol. 39, pp. 1-14, 2016.

[115] T. Brinkmann, J. Lillepärg, H. Notzke et al., "Development of $\mathrm{CO}_{2}$ selective poly(ethylene oxide)-based membranes: from laboratory to pilot plant scale," Engineering, vol. 3, no. 4, pp. 485-493, 2017.

[116] K. Schuldt, J. Pohlmann, S. Shishatskiy, and T. Brinkmann, "Applicability of PolyActive thin film composite membranes for $\mathrm{CO}_{2}$ separation from $\mathrm{C}_{2} \mathrm{H}_{4}$ containing multi-component gas mixtures at pressures up to 30 bar," Membranes, vol. 8 , no. 2, p. 27, 2018.

[117] C. H. Lau, P. T. Nguyen, M. R. Hill et al., "Ending aging in super glassy polymer membranes," Angewandte Chemie International Edition, vol. 53, no. 21, pp. 5322-5326, 2014.

[118] H. Wang, K. Zhang, J. P. H. Li et al., "Engineering plasticization resistant gas separation membranes using metalorganic nanocapsules," Chemical Science, vol. 11, no. 18, pp. 4687-4694, 2020.

[119] Z.-X. Low, P. M. Budd, N. B. McKeown, and D. A. Patterson, "Gas permeation properties, physical aging, and its mitigation in high free volume glassy polymers," Chemical Reviews, vol. 118, no. 12, pp. 5871-5911, 2018.

[120] S. M. Momeni and M. Pakizeh, "Preparation, characterization and gas permeation study of PSf/MgO nanocomposite membrane," Brazilian Journal of Chemical Engineering, vol. 30, no. 3, pp. 589-597, 2013.

[121] N. Prasetya, N. F. Himma, P. D. Sutrisna, I. G. Wenten, and B. P. Ladewig, "A review on emerging organic-containing 
microporous material membranes for carbon capture and separation," Chemical Engineering Journal, vol. 391, Article ID 123575, 2020.

[122] C. A. Scholes, A. Qader, G. W. Stevens, and S. E. Kentish, "Membrane pilot plant trials of $\mathrm{CO}_{2}$ separation from flue gas," Greenhouse Gases: Science and Technology, vol. 5, no. 3, pp. 229-237, 2015.

[123] M. Pfister, B. Belaissaoui, and E. Favre, "Membrane gas separation processes from wet postcombustion flue gases for carbon capture and use: a critical reassessment," Industrial \& Engineering Chemistry Research, vol. 56, no. 2, pp. 591-602, 2017.

[124] W. Wave, A. Szymezyk, N. Yave, and Z. Roslaniec, "Design, synthesis, characterization and optimization of PTT-b -PEO copolymers: a new membrane material for $\mathrm{CO}_{2}$ separation," Journal of Membrane Science, vol. 362, pp. 407-416, 2010.

[125] Y. Zhao, J. Lu, X. Liu et al., "Performance enhancement of polyvinyl chloride ultrafiltration membrane modified with graphene oxide," Journal of Colloid and Interface Science, vol. 480 , pp. 1-8, 2016

[126] Z. Wang, M. Fang, Q. Ma, Z. Zhao, T. Wang, and Z. Luo, "Membrane stripping technology for $\mathrm{CO}_{2}$ desorption from $\mathrm{CO}_{2}$-rich absorbents with low energy consumption," Energy Procedia, vol. 63, pp. 765-772, 2014.

[127] X. Shi, G. Tal, N. P. Hankins, and V. Gitis, "Fouling and cleaning of ultrafiltration membranes: a review," Journal of Water Process Engineering, vol. 1, pp. 121-138, 2014.

[128] K. Alharthi, Y. Christianto, A. Aguiar, A. Stickland, G. Stevens, and W. S. Kentish, "The impact of fly ash on membrane performance in post-combustion carbon capture applications," Industrial \& Engineering Chemistry Research, vol. 4, 2016.

[129] A. D. Ebner, M. L. Gray, N. G. Chisholm et al., "Suitability of a solid amine sorbent for $\mathrm{CO}_{2}$ capture by pressure swing adsorption," Industrial \& Engineering Chemistry Research, vol. 50, no. 9, pp. 5634-5641, 2011.

[130] A. Goeppert, M. Czaun, R. B. May, G. K. S. Prakash, G. A. Olah, and S. R. Narayanan, "Carbon dioxide capture from the air using a polyamine based regenerable solid adsorbent," Journal of the American Chemical Society, vol. 133, no. 50, pp. 20164-20167, 2011.

[131] M. Yuan, H. Teichgraeber, J. Wilcox, and A. R. Brandt, "Design and operations optimization of membrane-based flexible carbon capture," International Journal of Greenhouse Gas Control, vol. 84, pp. 154-163, 2019.

[132] A. K. Mishra and S. Ramaprabhu, "Nano magnetite decorated multiwalled carbon nanotubes: a robust nanomaterial for enhanced carbon dioxide adsorption," Energy and Environmental Science, vol. 4, no. 3, pp. 889-895, 2011.

[133] L. Zhao, E. Riensche, L. Blum, and D. Stolten, "Multi-stage gas separation membrane processes used in post-combustion capture: energetic and economic analyses," Journal of Membrane Science, vol. 359, no. 1-2, pp. 160-172, 2010.

[134] R. Pathare and R. Agrawal, "Design of membrane cascades for gas separation," Journal of Membrane Science, vol. 364, no. 1-2, pp. 263-277, 2010.

[135] M. Sandru, T.-J. Kim, W. Capala, M. Huijbers, and M.-B. Hägg, "Pilot scale testing of polymeric membranes for $\mathrm{CO}_{2}$ capture from coal fired power plants," Energy Procedia, vol. 37, pp. 6473-6480, 2013.

[136] S.-H. Choi, Y. Lee, and Y. Lee, "Pilot-scale multistage membrane process for the separation of $\mathrm{CO}_{2}$ from LNG-fired flue gas," Separation and Purification Technology, vol. 110, pp. 170-180, 2013.
[137] Y. Huang, T. C. Merkel, and R. W. Baker, "Pressure ratio and its impact on membrane gas separation processes," Journal of Membrane Science, vol. 463, pp. 33-40, 2014.

[138] F. Hussin and M. K. Aroua, "Recent trends in the development of adsorption technologies for carbon dioxide capture: a brief literature and patent reviews (2014-2018)," Journal of Cleaner Production, vol. 253, Article ID 119707, 2020.

[139] M.-B. Hägg and A. Lindbråthen, " $\mathrm{CO}_{2}$ capture from natural gas fired power plants by using membrane technology," Industrial \& Engineering Chemistry Research, vol. 44, no. 20, pp. 7668-7675, 2005.

[140] J. Pohlmann, M. Bram, K. Wilkner, and T. Brinkmann, "Pilot scale separation of $\mathrm{CO}_{2}$ from power plant flue gases by membrane technology," International Journal of Greenhouse Gas Control, vol. 53, pp. 56-64, 2016.

[141] Y.-F. Lin, J.-M. Chang, Q. Ye, and K.-L. Tung, "Hydrophobic fluorocarbon-modified silica aerogel tubular membranes with excellent $\mathrm{CO}_{2}$ recovery ability in membrane contactors," Applied Energy, vol. 154, pp. 21-25, 2015.

[142] G. M. Geise, H. B. Park, A. C. Sagle, B. D. Freeman, and J. E. McGrath, "Water permeability and water/salt selectivity tradeoff in polymers for desalination," Journal of Membrane Science, vol. 369, no. 1-2, pp. 130-138, 2011.

[143] I. C. E. Struik, Physical Aging in Amorphous Polymers and Other Materials, Elsevier, Amsterdam, Netherlands, 1978.

[144] L. M. Robeson, W. F. Burgoyne, M. Langsam, A. C. Savoca, and C. F. Tien, "High performance polymers for membrane separation," Polymer, vol. 35, no. 23, pp. 4970-4978, 1994.

[145] J. A. Otero, O. Mazarrasa, J. Villasante et al., "Three independent ways to obtain information on pore size distributions of nanofiltration membranes," Journal of Membrane Science, vol. 309, no. 1-2, pp. 17-27, 2008.

[146] R. Bounaceur, N. Lape, D. Roizard, C. Vallieres, and E. Favre, "Membrane processes for post-combustion carbon dioxide capture: a parametric study," Energy, vol. 31, no. 14, pp. 2556-2570, 2006.

[147] L. Peters, A. Hussain, M. Follmann, T. Melin, and M.-B. Hagg, " $\mathrm{CO}_{2}$ removal from natural gas by employing amine absorption and membrane technology-a technical and economical analysis," Chemical Engineering Journal, vol. 172, no. 2-3, pp. 952-960, 2011

[148] X. He, M.-B. Hägg, and T.-J. Kim, "Hybrid FSC membrane for $\mathrm{CO}_{2}$ removal from natural gas: experimental, process simulation, and economic feasibility analysis," AIChE Journal, vol. 60, no. 12, pp. 4174-4184, 2014.

[149] E. Favre, "Carbon dioxide recovery from post-combustion processes: can gas permeation membranes compete with absorption?" Journal of Membrane Science, vol. 294, no. 1-2, pp. 50-59, 2007.

[150] C. E. Powell and G. G. Qiao, "Polymeric $\mathrm{CO}_{2} / \mathrm{N}_{2}$ gas separation membranes for the capture of carbon dioxide from power plant flue gases," Journal of Membrane Science, vol. 279, no. 1-2, pp. 1-49, 2006.

[151] A. F. Ismail and A. Mansourizadeh, "A comparative study on the structure and performance of porous polyvinylidene fluoride and polysulfone hollow fiber membranes for $\mathrm{CO}_{2}$ absorption," Journal of Membrane Science, vol. 365, no. 1-2, pp. 319-328, 2010.

[152] C.-B. Lee, S.-W. Lee, J.-S. Park et al., "Long-term $\mathrm{CO}_{2}$ capture tests of Pd-based composite membranes with module configuration," International Journal of Hydrogen Energy, vol. 38, no. 19, pp. 7896-7903, 2013. 
[153] M. Czyperek, P. Zapp, H. J. M. Bouwmeester, M. Modigell, K. Ebert, and I. Voigt, "Gas separation membranes for zeroemission fossil power plants: membrain," Journal of Membrane Science, vol. 359, pp. 160-172, 2010.

[154] R. Al-Attabi, Y. Morsi, J. A. Schütz, D. Cornu, M. Maghe, and L. F. Dumée, "Flexible and reusable carbon nano-fibre membranes for airborne contaminants capture," Science of the Total Environment, vol. 754, Article ID 142231, 2021.

[155] L. S. White, X. Wei, S. Pande, T. Wu, and T. C. Merkel, "Extended flue gas trials with a membrane-based pilot plant at a one-ton-per-day carbon capture rate," Journal of Membrane Science, vol. 496, pp. 48-57, 2015.

[156] T. Brinkmann, J. Pohlmann, M. Bram et al., "Investigating the influence of the pressure distribution in a membrane module on the cascaded membrane system for post-combustion capture," International Journal of Greenhouse Gas Control, vol. 39, pp. 194-204, 2015.

[157] R. C. Selley and S. A. Sonnenberg, "Sedimentary basins and petroleum systems," in Element of Petroleum Geology, pp. 377-426, Elsevier, Amsterdam, Netherlands, 2015.

[158] A. Kumar Shukla, Z. Ahmad, M. Sharma et al., "Advances of carbon capture and storage in coal-based power generating units in an Indian context," Energies, vol. 13, no. 16, p. 4124, 2020.

[159] M. Hefny, C. Qin, M. O. Saar, and A. Ebigbo, "Synchrotronbased pore-network modeling of two-phase flow in Nubian sandstone and implications for capillary trapping of carbon dioxide," International Journal of Greenhouse Gas Control, vol. 103, Article ID 103164, 2020.

[160] H. De Coninck and S. M. Benson, "Carbon dioxide capture and storage: issues and prospects," Annual Review of Environment and Resources, vol. 39, no. 1, pp. 243-270, 2014.

[161] A. I. Osman, M. Hefny, M. I. A. Abdel Maksound, A. M. Elgarahy, and D. W. Rooney, "Recent advances in carbon capture storage and utilization technologies: a review," Environmental Chemistry Letters, vol. 19, pp. 797-849, 2021.

[162] Y. Alqaheem, A. Alomair, M. Vinoba, and A. Perez, "Polymeric gas-separation membranes for petroleum refining," International Journal of Polymer Science, vol. 2017, Article ID 4250927, 19 pages, 2017. 